\title{
Single, Stretched Membrane, Structural Module Experiments
}

Richard L. Wood

February 1986

Prepared under Task No. 5111.31

FTP No. 05-510-85

Solar Energy Research Institute

A Division of Midwest Research Institute

1617 Cole Boulevard

Golden, Colorado 80401

Prepared for the

U.S. Department of Energy

Contract No. DE-AC02-83CH10093 


\section{PREFACE}

The research and development described in this document was conducted within the U.S. Department of Energy's (DOE) Solar Thermal Technology Program. The goal of this program is to advance the engineering and scientific understanding of solar thermal technology and to establish the technology base from which private industry can develop solar thermal power production options for introduction into the competitive energy market.

Solar thermal technology concentrates the solar flux using tracking mirrors or lenses onto a receiver where the solar energy is absorbed as heat and converted into electricity or incorporated into products as process heat. The two primary solar thermal technologies, central receivers and distributed receivers, employ various point- and 1 ine-focus optics to concentrate sunlight. Current central receiver systems use fields of heliostats (two-axis tracking mirrors) to focus the sun's radiant energy onto a single, towermounted receiver. Point-focus concentrators up to 17 meters in diameter track the sun in two axes and use parabolic dish mirrors or Fresnel lenses to focus radiant energy onto a receiver. Troughs and bowls are line-focus tracking reflectors that concentrate sunlight onto receiver tubes along their focal lines. Concentrating collector modules can be used alone or in a multimodule system. The concentrated radiant energy absorbed by the solar thermal receiver is transported to the conversion process by a circulating working fluid. Receiver temperatures range from $100^{\circ} \mathrm{C}$ in low-temperature troughs to over $1500^{\circ} \mathrm{C}$ in dish and central receiver systems.

The Solar Thermal Technology Program is directing efforts to advance and improve each system concept through solar thermal materials, components, and subsystems research and development and by testing and evaluation. These efforts are carried out under the technical direction of DOE and its network of national laboratories that works with private industry. Together they have established a comprehensive, goal-directed program to improve performance and provide technically proven options for eventual incorporation into the nation's energy supply.

To successfully contribute to an adequate energy supply at reasonable cost, solar thermal energy must be economically competitive with a variety of other energy sources. The Solar Thermal Program has developed components and system-level performance targets as quantitative program goals. These targets are used in planning research and development activities, measuring progress, assessing alternative technology options, and developing optimal components. These targets will be pursued vigorously to ensure a successful program.

In pursuit of these goals SERI researchers are vigorously investigating innovative schemes, such as the stretched-membrane mirror structure, that can improve the cost and performance of solar thermal systems. The experimental work reported here is part of the final phase of the Solar Energy Research Institute's (SERI) successful work in stretched metal membrane heliostat 
research. Already, the stretched membrane technology is being incorporated in the solar thermal development program, and large prototype hardware is being designed and built for Sandia National Laboratory at Livermore using the structural understanding developed at SERI.

The author wishes to thank Marshall Buhl, Girard Glinsky, Michael Doll, David Simns, and L. M. Murphy of SERI, G. W. Hannaway of G. W. Hannaway and Associates, Daniel Sall is of Dan-Ka Products, Inc., and James Wolfe of A.T.A., for their invaluable assistance in completing this project. Thanks also go to Thomas Brumleve for his review of and comments on this paper. Special thanks go to Michael Doll for contributing his special talents and through testing of the models described here.

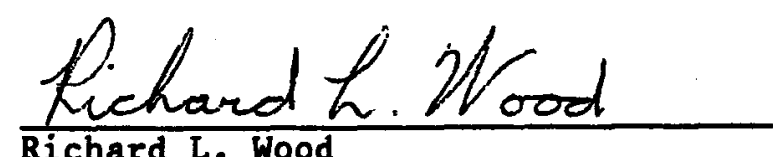

Approved for

SOLAR ENERGY RESEARCH INSTITUTE

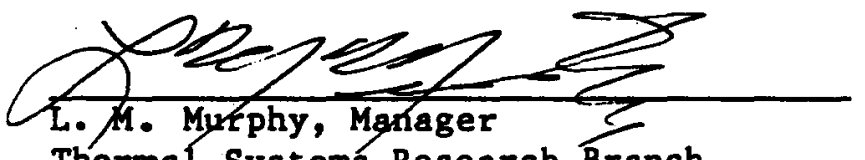

Thermal Systems Research Branch

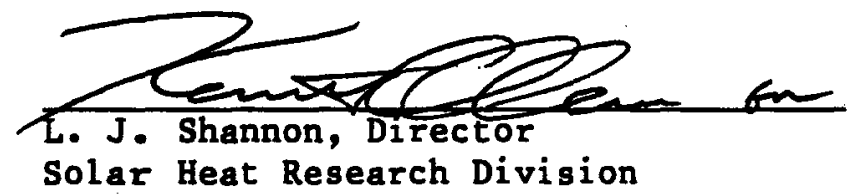




\section{SUMAMARY}

\section{Objective}

The research objective was to achieve a greater understanding of the structural response of stretched-membrane modules, to correlate with prior analysis findings, and to determine the validity of the approximate mathematical models that were developed to describe module performance.

\section{Discussion}

We conducted experiments to verify and augment the structural analyses and models produced by SERI to support the solar thermal program in developing cost-effective heliostats. This report describes the testing of four stretched-membrane structural modules at the Solar Energy Research Institute (SERI) from June 1984 through May 1985. Included are descriptions of the construction of the 3-meter-diameter test modules, the development and operation of a sensitive system for measuring minute deflections in the surface contour of the modules, and the relationship between actual structural behavior and analytical predictions. The experiments described here are a significant part of the final phase of research on metal, stretched-membrane heliostats at SERI.

To make measuring deflection trends easier and more precise, we based the modules on 3-meter-diameter ring frames that were intentionally much weaker than would be used in production. They included a means for varying the membrane tension and for supporting the module frame at three points, equally spaced around the ring. One of the modules was later given a rigid bond between the membrane and the frame, a structural change that we expected would affect the out-of-plane bending stiffness of the module. A reflective polymer film was 1 aminated to the $0.012-i n .-t h i c k$ stainless steel structural membrane to demonstrate the structure's role as a heliostat mirror, and to use the optical shape-sensing technique.

The modules tested were mounted vertically on an enclosed framework. We could support the weight of the module in either of two ways. Each supporting method placed a different external load on the module. The enclosure allowed a slight vacuum to be pulled behind the module to simulate a uniform wind loading normal to the mirror's surface. The air seal around the rim of the mirror to the enclosure imposed a slight load on the module that affected the results somewhat.

We used a virtual image method developed for this project to determine the shape of the membrane's surface under various loading conditions. Using a video camera $15+$ meters $(\sim 53 \mathrm{ft}$ ) away from the mirror, we observed and recorded the virtual image of a target grid as reflected by the mirror's surface. At this distance, very small deviations in the mirror's surface cause marked distortions in the virtual image, as in a fun-house mirror. The image was digitized and stored on a microcomputer for analysis. Using the law of reflection and analytic geometry, we can compute the surface slopes of a sampling of points on the surface from measurements of the image position. 
We assumed a generalized modal (Fourier series) equation with arbitrary coefficients for the shape of the membrane that was consistent with numerous permissible modes of deformation for the module. A least-squares method was used to fit the equation to the sampling of surface slope data. The assumed equation fit all of the data very well, and only the expected terms showed up in the results.

We conducted six series of tests on four mirror modules: three pneumatically attached modules with their weight suspended at the bottom support, two pneumatically attached modules with their weight suspended from the upper mounts, and one rigidly attached module with its weight suspended at the bottom mount. We varied the membrane tension and simulated various uniform wind loads with the vacuum enclosure.

\section{Conclusions and Recommendations}

We found that the dominant module response in the above tests was consistent with prior SERI analyses. Also, with the simple analysis method, the measured membrane and frame deformations induced by the pressure loading and the periodic support constraints averaged within $17 \%$ of the values predicted, even though idealized support conditions varied significantly from the true conditions.

The simple analytical model is quite adequate for designing and sizing singlemembrane modules if the initial imperfections and their amplification are appropriately controlled. We found that initial imperfections corresponding to the primary $n=2$ deformation mode can be quite important. The $n=2$ load deformation response is quite complex, as the more detailed NASTRAN analysis of larger modules confirmed. More specifically, the tests confirmed that coupling may occur that involves axisymmetric dishing $(n=0)$, the $n=2$, and $n=3$ deflection modes because the $n=2$ deflection reorients itself under pressure load so one of its valleys falls atop one of the $n=3$ valleys. Some cases show an associated amplification of the $n=2$ magnitude, and others, where the initial $n=2$ magnitude was large, show that it was attenuated by load. The prior NASTRAN computer code analysis shows that a nonlinear coupling occurs between the in-plane frame deformation and the out-of-plane $n=2$ modes of deformation. This coupling increases dramatically when a pressure load is placed on the membrane and the membrane tension load is simultaneously near or above the out-of-plane buckling load for the frame only (no membrane restoring force).

To avoid potential problems resulting from the fundamental $n=2$ deformation phenomena, we advise using either relatively stiffer ring frames or more than three support points on the ring frame. With more than three supports, most or all of the $n=2$ deformation and its subsequent amplification might be removed.

We did not find any significant differences between the rigidly bounded and hydraulically attached single-membrane designs. 
TABLE OP CONTEUTS

Page

1.0 Introduction....................................... 1

2.0 The structural Tests................................. 5

2.1 Measurement Method................................ 7

2.2 Data Analysis..................................... 13

3.0 Findings.......................................... 16

3.1 Amplification of Initial Imperfections--n $=2$ Deformation...... 16

3.2 Support-Induced $n=3$ Deflection..................... 17

4.0 Conclusions and Recommendations......................... 20

5.0 References....................................... 22

Appendix A Test Results....................................... 23

Appendix B Elements of Video Observation, Digitization, and

Analysis System.................................. 39

Appendix C Error Analysis: Sources of Uncertainty in Results......... 42

Selected Distribution List................................ 46 
1-1 Mirror Structural Test Module............................. 3

1-2 Pneumatic Tensioning Method............................ 4

2-1 Module Support Points................................. 6

2-2 Virtual Image Testing system........................... 8

2-3 Images Seen Under Test Conditions........................ 9

$2-4$ Video Image Analysis system........................... 10

2-5 Mirror Distortions Appear Relatively Larger at Greater Distances... 12

2-6 Garbled Virtual Image............................... 13

2-7 Error Vector Definition............................... 15

3-1 Wind Load Simulator Rim Seal............................ 19

A-1 Amplitude of Primary Mode $(n=2)$ Deflection Component in WindLoaded, Single-Membrane Modules.......................... 28

A-2 Orientation of Primary Mode $(n=2)$ Deflection Component in WindLoaded, Single-Membrane Modules, Weight Support at Bottom.........

A-3 Orientation of Primary Mode $(n=2)$ Deflection Component in WindLoaded, Single-Membrane Modules, Weight Support at Upper Brackets..

A-4 Peak-to-Peak Magnitude ( $=2 \times$ amplitude) of Support-Induced $(n=3)$ Deflection Component in All Wind-Loaded, Single-Membrane Modules.............................................

A-5 Peak-to-Peak Magnitude (= $2 \times$ amplitude) of Support-Induced $(n=3)$ Deflection Component on Single-Membrane Modules with

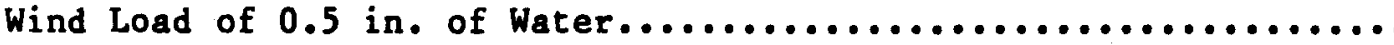

A-6 Peak-to-Peak Magnitude (= $2 \times$ amplitude) of Support-Induced $(n=3)$ Deflection Component on Single-Membrane Modules with Wind Load of 1.0 in. of Water.............................

A-7 Peak-to-Peak Magnitude (= $2 \times$ amplitude) of Support-Induced $(n=3)$ Deflection Component on Single-Membrane Modules with Wind Load of 1.5 in. of Water............................ 33

A-8 Digitized Video Picture of Test M01C400В000.................. 34

A-9 Implied Membrane and Rim Shapes from Test M01C400B000.......... 35 


\section{LIST OF FIGURES (concluded)}

$\underline{\text { Page }}$

A-10 Digitized Video Picture of Test MO1C400B150.................. 34

A-11 Implied Membrane and Rim Shapes from Test M01C400B150.......... 35

A-12 Digitized Video Picture of Test M03C400B000................. 36

A-13 Implied Membrane and Rim Shapes from Test M03C400B000.......... 37

A-14 Digitized Video Picture of Test M03C400B150.................. 36

A-15 Implied Membrane and Rim Shapes from Test M03C400B150........... 37

A-16 The Effect of External Bending Moment...................... 38

B-1 Video Image Analysis system............................ 41

C-1 Magnified views of the Mirror's Surface...................... 43

C-2 Data Analysis Is Complicated by Local Defects.................. 43

C-3 Effect of Large-Scale Ripples........................... 43

C-4 Direct View of Camera Calibration Target.................... 44 


\section{LIST OF TABLES}

$\underline{\text { Page }}$

2-1 Module Test Series Load and Support Combinations............... 5

A-1 Apparent Membrane Shape from Curve Fit to Slope Data............. 24 


\section{SECTION 1.0}

\section{INTRODUCTION}

Large, structurally efficient and optically accurate solar reflectors and concentrators for solar thermal applications are feasible using the stretchedmembrane concept. With this concept a high-strength structural membrane coated with a highly reflective surface is stretched uniformly on a frame (typically a lightweight, hollow, toroidal structure). The stretched-membrane concept is a method of attaining and supporting a large, optically accurate surface using 1 ighter weight and lower cost structures than are otherwise currently possible (Murphy 1983). This concept is also especially suitable for using polymer reflectors and structural membranes, which may further reduce weight and cost and improve handling at the factory, in the field, and in transport.

Because of these very attractive potential benefits, the Department of Energy (DOE) has been sponsoring research on the stretched-membrane concept for some time. Much of the prior research, which has consigted of closely coordinated experimental and analytical efforts, is described in earlier publications (Murphy 1983; and Murphy and Sallis 1984) and in reports currently being prepared (Murphy 1985; Murphy, Sallis, and Simms, forthcoming). Most of the prior experimental effort was directed at demonstrating the feasibility of the hardware, and the gross structural performance, providing initial configurations for further comprehensive analysis based on qualitative optical assessments, and identifying and evaluating such limiting engineering issues as the design of the membrane-to-frame attachment. However, none of the experiments carried out so far have yielded detailed quantitative information on the optical and structural response of stretched-membrane modules.

This report describes tests of four stretched-membrane structural modules conducted at the Solar Energy Research Institute (SERI) from June 1984 through May 1985. Included are descriptions of the construction of the 3-meterdiameter test modules, the development and operation of a sensitive system for measuring minute deflections in the surface contour of the modules, and comparisons between actual structural behavior and analytical predictions. The experiments described here are a significant part of the final research phase on metal stretched-membrane heliostats at SERI.

We fabricated and tested 3-meter-diameter modules to experimentally study the structural and optical responses of various designs when they are subjected to loading and operating conditions anticipated for commercial versions. Further, this experimental research helped to verify the analysis done to date and pointed out where further analysis is still needed. These experiments also helped identify crucial design issues and problem areas that might affect the development and design process being directed by the Sandia National Laboratories at Livermore (SNLL) in California.

The analysis to date has been used to identify and study the dominant response mechanisms in stretched-membrane module designs and to predict trends in the optical and structural responses of stretched-membrane modules to numerous design variables (Murphy and Sallis 1984). The experiments described here 
were not specifically directed at matching the analytical idealizations. Rather, we designed the experiments to induce and describe the numerous response mechanisms anticipated with stretched-membrane modules, modeled or not. Furthermore, in several instances we exaggerated certain response mechanisms anticipated in the eventual commercial designs to study them better. As an example, no analysis to date has considered in-plane loading effects because they are believed to be generally unimportant; however, the test configuration amplified these effects considerably beyond what is considered likely in a real field environment. This allows us to make an upper bound estimate of the effect of these loadings.

We performed these experiments on mirror modules fabricated by Dan-Ka Products of Denver. Figure 1-1 shows one of the three single-membrane modules produced.

Each module was based on a 3-meter-diameter ring frame rolled from 1 in. $x 3$ in. $\times 0.062$ in. hollow steel box beam. This frame cross section is intentionally much weaker than what would be used in production but was predicted to have a suitable balance between in-plane, out-of-plane, and torsional stiffness to show trends applicable to production designs. Since the rolling process did not produce rings that were flat enough for our purpose, shorter individual sections were rolled, flattened, and welded together, and a special $\mathrm{jig}$ was used to bend the fabricated rings into a nearplanar shape. A 0.012-in.-thick stainless steel membrane is held in tension on each circular hoop. The membrane itself was made by butt seaming four 33-in.-wide sheets (from coiled stock) with epoxy/fiberglass tape, since wide sheets of the needed thin-gauge material were not available. To illustrate the suitability of the structure as a heliostat mirror substrate and to utilize the virtual image surface characterization method described in Section 2.1 , a reflective surface of $3 M^{\prime} \mathrm{s}$ ECP244, an aluminized acrylic film with an adhesive backing, was applied to the face of this structural membrane. Although we do not expect this reflective surface to be used on actual heliostats because of its relatively poor reflectivity, it was readily available, inexpensive, and quite suitable for our optical shape measurements.

Al1 three modules were initially delivered in the same form. The membrane attachment scheme used an inflated "inner tube" to apply a uniform force between the frame and membrane (see Figure 1-2). The scheme is one that Dan-Ka had developed and used on earlier test modules. This scheme is not necessarily recommended for prototype or commercial designs, but it was easy to fabricate and, most significantly, it allows us to vary the membrane tension easily by changing the air pressure in the bladder. This scheme provided a fairly pliant attachment between the membrane and frame, although we expect the friction at the point where the membrane rides over the edge of the frame to increase its rigidity somewhat. Since the pneumatic bladder acts like a nonlinear spring, allowing radial movement while supplying a restoring force that varies relatively slowly with ring displacement, we expected the membrane tension to remain fairly uniform regardless of the deflection of the ring frame. Prior analysis (Murphy and Sallis 1984; Murphy, forthcoming; Murphy, Sallis, and Simms, forthcoming) indicated that this restoring property would not greatly affect the behavior of the module; even single-membrane 


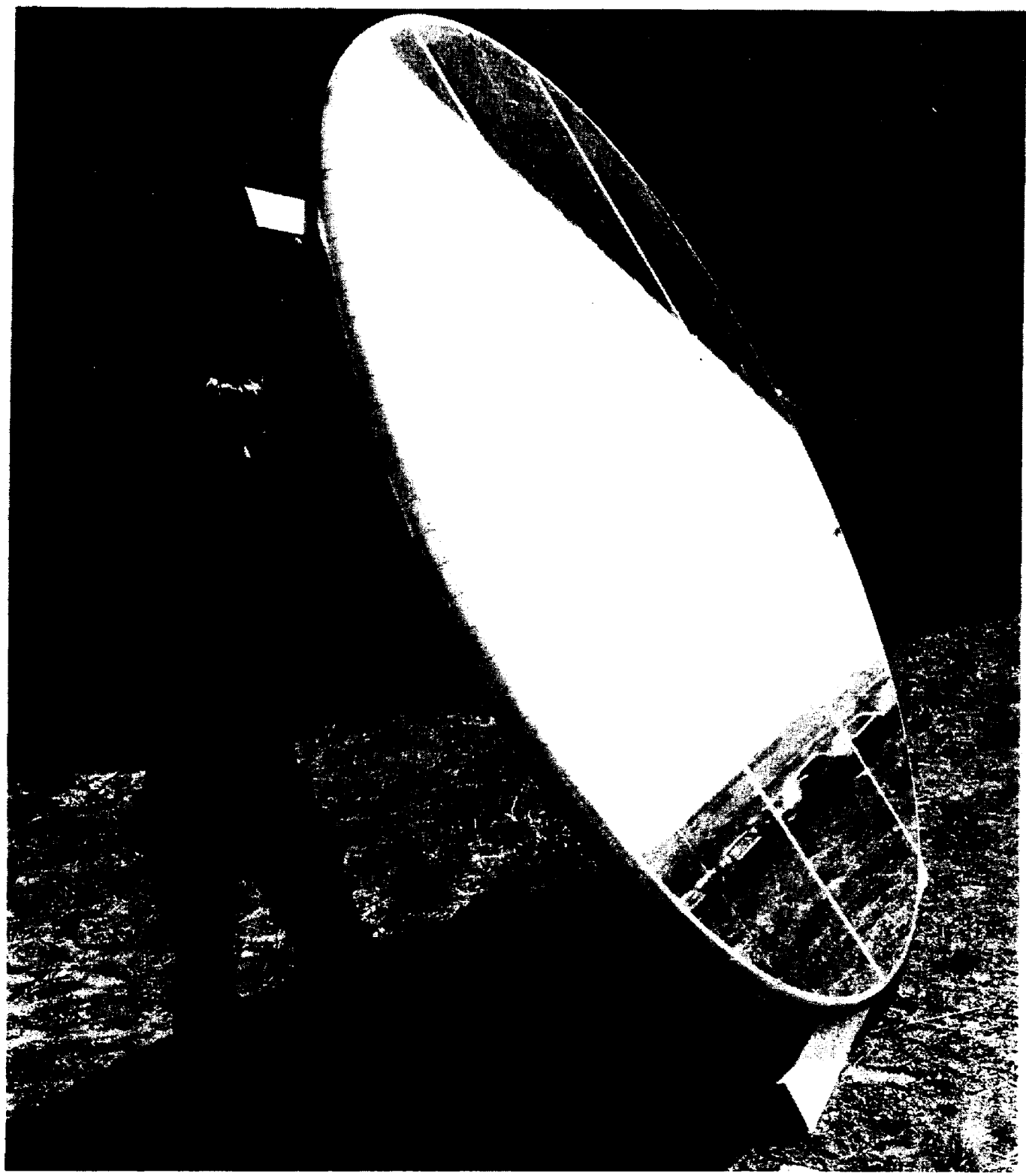

Figure 1-1. Mirror structural Test Module. Three 3-meter-diameter, stretched-membrane, structural test modules were fabricated for this test by Dan-Ka Products of Denver.

designs in which the membrane has a perfectly rigid radial constraint and no circumferential resistance show uniform membrane tension under most loading conditions.

After thoroughly testing one of these modules to characterize its structural response in the pliant, pneumatically attached configuration, we sent this module back to Dan-Ka to have the membrane rigidly bonded to the frame at a specified tension. While the frame was held flat on the straightening jig, workers tensioned the membrane to the desired level using the pneumatic 


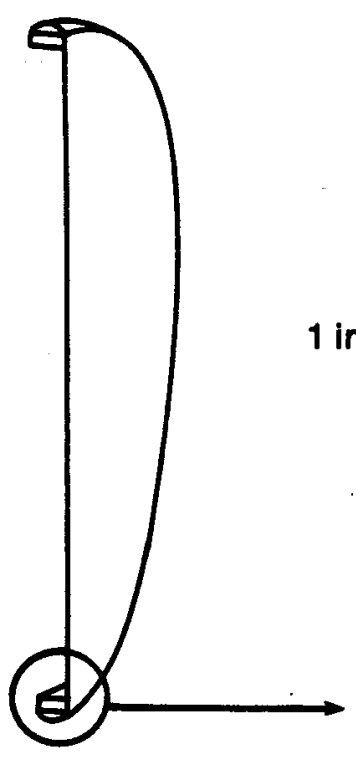
in. $\times 3$ in. $\times 0.062$ in.
box ring frame

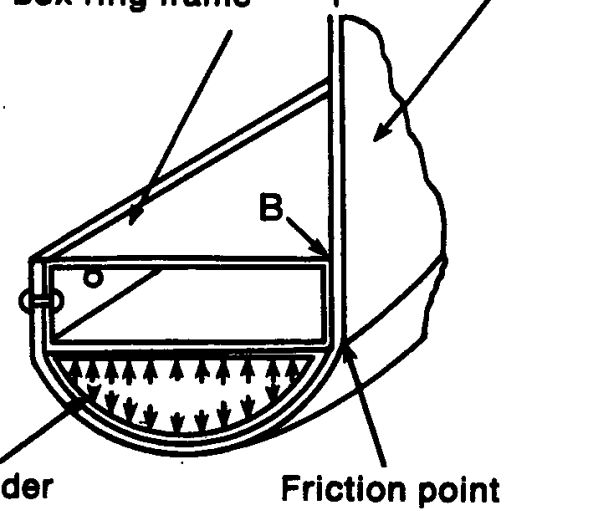

Figure 1-2. Pneumatic Tensioning Method. Membrane tension was varied by changing the air pressure in the "inner tube." The fixed attachment was obtained by injecting a bonding agent at point $B$.

bladder and injected an adhesive bonding agent into the joint between the membrane and the frame (point $B$ in Figure 1-2). We predicted that this attachment approach would result in a somewhat more rigid structure than the models with more pliant attachments. The rigidly attached membrane greatly affects out-of-plane bending by contributing additional moment-of-inertia to the frame, much as a flange might if welded to the top or bottom of the frame. We call this the "flange effect." Recent calculations show that this flange effect is enhanced in double-membrane designs because of the coupling between the roll and bending of the frame. 
SECTION 2.0

THE STRUCTURAL TESTS

A goal of these tests was to observe the static shape of the stretchedmembrane and frame structure as a function of membrane tension and simulated wind load with some variation in module support mountings. Table 2-1 shows a matrix of the loading conditions to which the various modules were subjected.

The modules were supported vertically from three points on the ring, as shown in Figure 2-1. Three points were chosen to give the ring frame the greatest freedom to distort so we could study all its natural deflection modes.

We designed a fixture that allows the weight of the structure to be carried either on the bottom support only or on the two top supports jointly. With this design the support attachments not carrying the weight cannot apply any radial force or bending torque to the ring frame. Nonuniform torques on the frame result in nonuniform out-of-plane frame deformation and associated surface deformations. Nevertheless, it was impractical to remove all extraneous torques from those supports that were carrying some of the module's weight. When the weight was carried by the bottom support, a fairly short moment arm (shown in Figure 2-1) caused a small but significant torsional moment in the ring frame at that point. When the weight was carried on the upper two supports, a relatively long resulting moment arm was operative at the supports. Even if the module weight is shared equally by each of the upper two supports (which we cannot guarantee and which we suspect was not the case), the resulting torques produced have components both in out-of-plane bending and in frame torsion.

Table 2-1. Module Test Series Load and Support Combinations (in approximately chronological order)

\begin{tabular}{ccllc}
\hline $\begin{array}{c}\text { Series } \\
\text { Designation }\end{array}$ & $\begin{array}{c}\text { Mirror } \\
\text { Module }\end{array}$ & $\begin{array}{c}\text { Module } \\
\text { Weight } \\
\text { Support }\end{array}$ & $\begin{array}{c}\text { Membrane } \\
\text { Tensions } \\
\left(1 \mathrm{~b}_{\mathrm{f}} / \text { in. }\right)\end{array}$ & $\begin{array}{c}\text { Vacuum } \\
\text { Loading } \\
\left(\text { in. }_{2} \text { O) }\right.\end{array}$ \\
\hline M02B & 2 & bottom & $25,98,58$ & $0.0-1.5$ \\
M02T & 2 & upper & $25,100,58$ & $0.0-2.0$ \\
M03B & 3 & bottom & $33,100,66$ & $0.0-2.5$ \\
M04B & $4(01 \mathrm{~d} 2)$ & bottom & $97^{\mathrm{b}}, 47^{\mathrm{b}}$ & $0.0-2.0$ \\
M01B & 1 & bottom & $33,100,66$ & $0.0-2.5$ \\
M01T & 1 & upper & $33,100,66$ & $0.0-2.5$ \\
\hline
\end{tabular}

${ }^{a}$ See Figure 2-1 for a description of the support details.

${ }^{b}$ As indicated by amount of axisymmetric dishing. Not directly measurable since the pneumatic tensioning mechanism was disabled. 


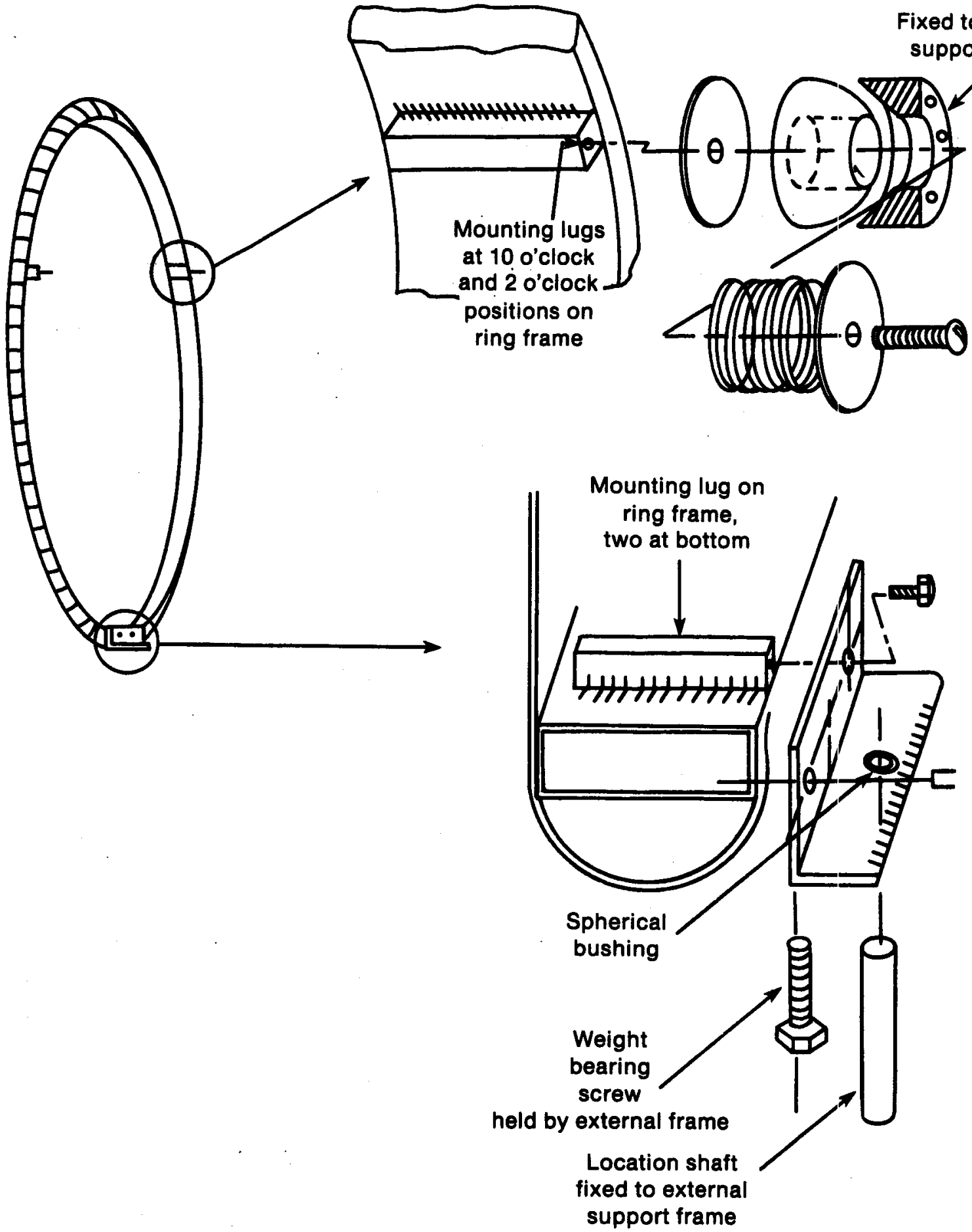

Figure 2-1. Module Support Points. Mounting brackets used spherical joints to avoid extraneous frame bending moments. Module weight could be carried at the bottom mount, or, if the lower support jackscrew is removed, it could be lowered onto the upper two mounts. 
This support fixture was mounted in an enclosed, sheet metal box, and a commercial vacuum cleaner was used to pull a slight vacuum (up to 2.5 in. of $\mathrm{H}_{2} \mathrm{O}$ in the high tension tests) inside the enclosure to simulate wind loading on the mirror module. The face of the box had a seal fit close to the rim of the mirror. The box and the seal were constructed so as to avoid adding any significant amount of external force onto the rim of the module. Pressure taps were installed at six points in the enclosure so that we could measure the front-to-back pressure difference to ensure it was uniform across the mirror. The net force of the vacuum on the mirror module was normal to the membrane surface and, therefore, strictly horizontal. The three module supports were the only reaction to the net pressure force on the module points, as noted.

The three pneumatically tensioned modules were initially tested with the weight supported at the bottom attachment at low tension first, between 25 and $33 \mathrm{lb} / \mathrm{in} .$, then high tension, typically $100 \mathrm{lb} / \mathrm{in}$. Finally, the tension was dropped to an intermediate tension, between 58 and $67 \mathrm{lb} / \mathrm{in}$. On two of the modules we repeated the sequence with the weight supported by the upper two brackets (see Table 2-l).

Later, we again had the membrane rigidly bonded to the frame on one of these modules. The first rigid bond configuration was preset at approximately $100 \mathrm{lb} / \mathrm{in}$. After testing it at various wind loads, we removed the membrane and reattached it at approximately $50 \mathrm{lb} / \mathrm{in}$. and then retested it.

\subsection{MEASURGIGTI METHOD}

The test method described here was specifically designed for performing the structural response tests on these 3-meter-diameter modules. The test method is a flexible laboratory research tool that can be adapted for numerous tests but is not directly applicable to heliostat mirrors in the field.

The experiments called for a sensitive detection scheme. Surface slope errors on the order of a few milliradians greatly affect the size and shape of a reflected spot on a central receiver. These slope errors translate into very small surface deformations (on the order of a millimeter for the 3-meterdiameter modules) and it would be difficult and imprecise at best to directly measure surface displacements this small on a 3-meter-diameter structure. The virtual image method developed for these tests is very sensitive to small deflections of this order and made it possible to map the shape of the membrane surface accurately over a wide range of deflections, even showing the extent of manufacturing error in modules with no load.

Figure 2-2 schematically shows the features of the method we selected. The observer at point 0 (in this case, the video camera) sees a reflection of the checkerboard grid in the mirror at the right. If the mirror is perfectly flat, the virtual image will appear undistorted, neither magnified nor reduced. Rather, it will appear full size, as if the observer were looking through a window, seeing an identical checkerboard a distance $L$ behind the window (mirror). Deviations in the direction of the mirror's surface normal will, of course, cause distortions in the observed virtual image, as with a fun-house mirror. Figure 2-3 shows the video-recorded images of a relatively 

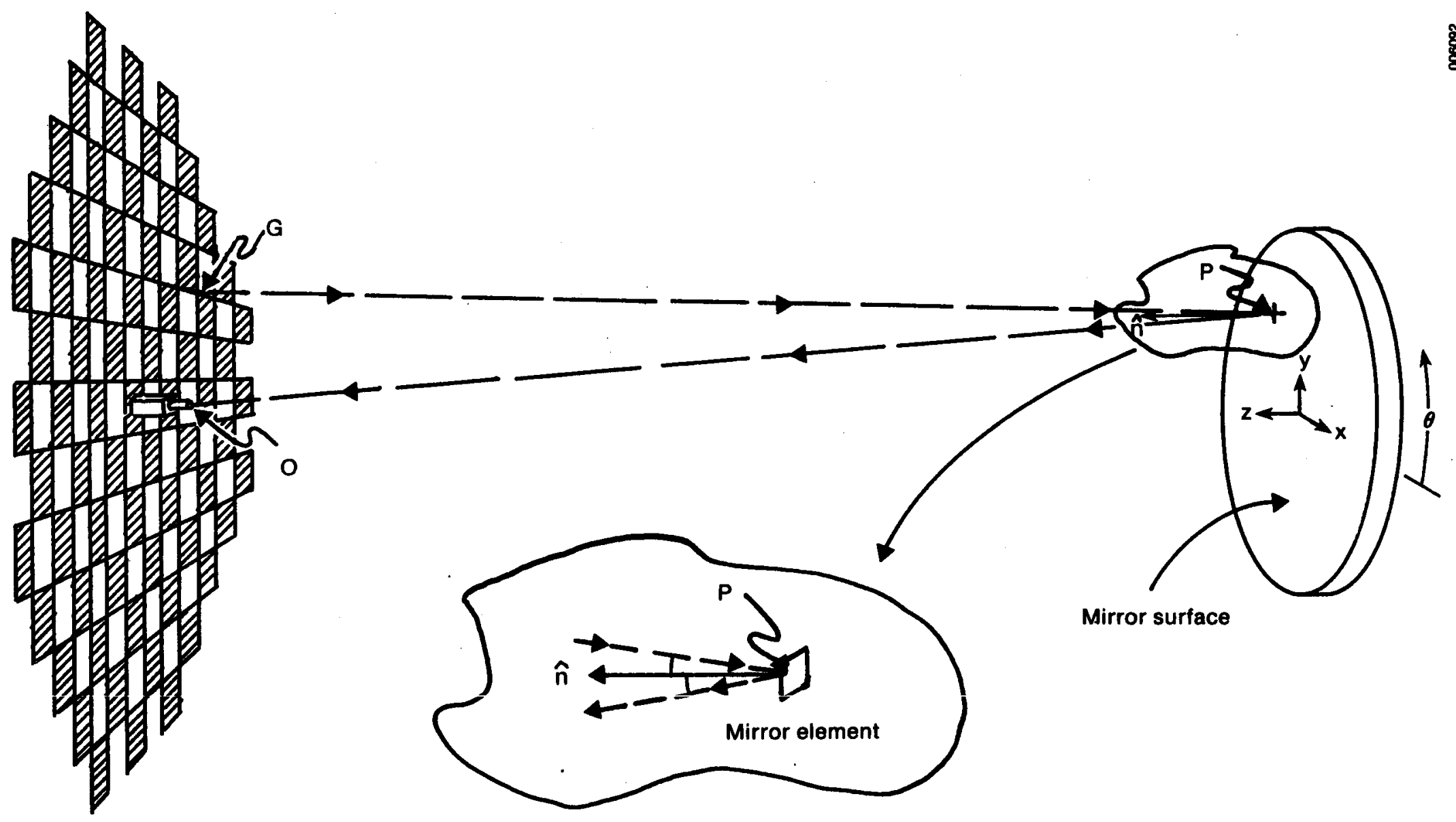

Figure 2-2. Virtual Image Testing System. A video camera at point 0 is used to view and record the reflected image of the test pattern. At long range, slight distortions of the mirror's surface cause marked distortions in the image, as in a fun-house mirror. 
flat (a) and a vacuum-loaded (b) membrane. Note that in the loaded mirror, the image is magnified and the grid is also distorted, indicating nonuniform, out-of-plane deflection of the frame to which the membrane is attached, which corresponds to the periodic support pattern.

We obtain quantitative shape information from this view by applying the law of reflection and some elementary vector algebra. In Figure 2-2, consider the point $G$ on the checkerboard grid that the observer sees by looking "through" point $P$ on the mirror. Knowing the precise location of point $G$ on the grid with respect to the observer at point 0 and comparing that location with the measured location of the image point $P$ (relative to the mirror's center or rim), we can define the rays $G P$ and $P O$. By the law of reflection, the normal to the mirror surface at point $P$ must bisect the angle between 1 ines $G P$ and $P O$, as shown in the inset. Thus, the surface normal direction is defined.

In implementing this scheme we have configured and assembled a system of electronic and optical components (see Figure 2-4), including a precision video camera with a telephoto lens, a microcomputer, and a video image digitizer (see Appendix B for a more complete description). Software on the microcomputer accesses the image data on the digital framestore and by pattern recognition identifies point $P$ in the virtual image and determines its $x$ and $y$ coordinates (or $r$ and $\theta$ ) relative to known points in the direct view of the camera. Appendix $C$ contains more details about this process.

For this determination to be exact we must know the axial or $z$ coordinate of point $P$, which can be

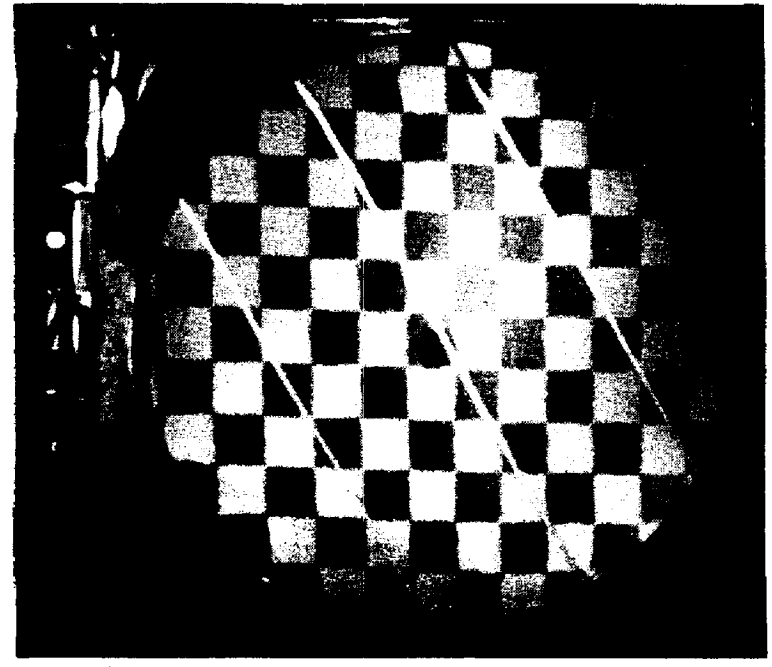

(a) Undistorted image in an unloaded mirror

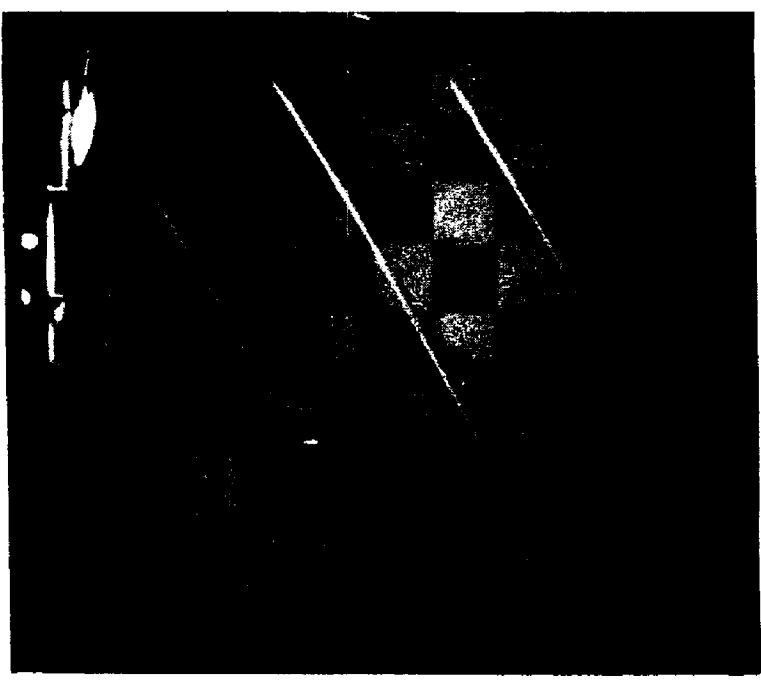

(b) Mirror with slight vacuum behind it

Figure 2-3. Images Seen Under Test Conditions. In (a), we see the nearly undistorted image seen in an unloaded mirror; in (b), the same mirror with a slight vacuum pulled behind it to simulate a wind load. Note the magnification of the image due to the concavity of the surface. Also note that the squares are warped in places, indicating out-of-plane bending of the ring frame. 


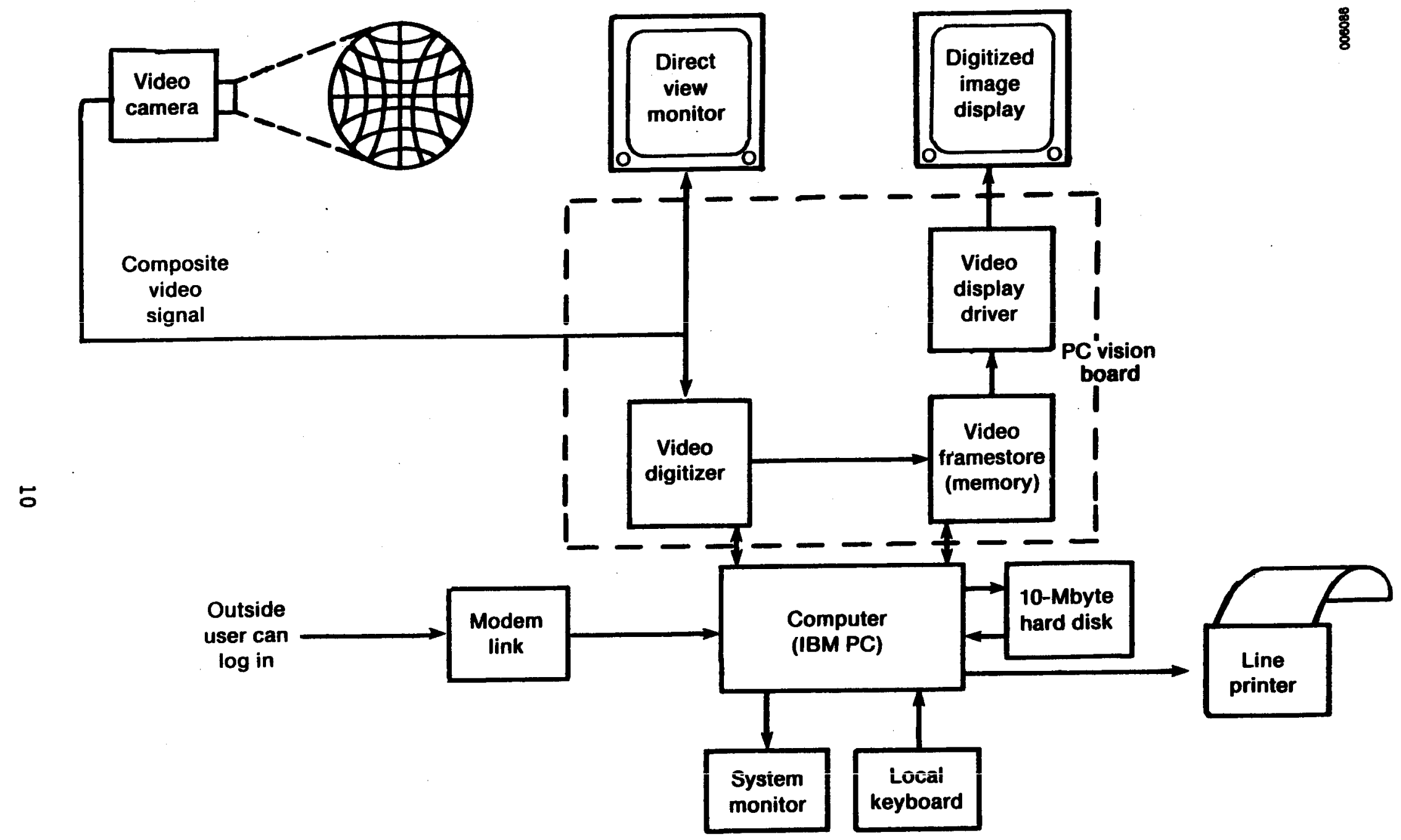

Figure 2-4. Video Inage Analysis System. Available digital hardware and software were used, along with SERI software, to extract information from the recorded video images needed to determine the exact shape of the mirror. 
envisioned as two components: the nominal distance from the observer to the nominal reflector plane and the displacement of the membrane surface from the nominal reflector plane (the quantity we are hoping to deduce as a result of this process). However, by making the distance between observer and mirror very large compared with the maximum $z$ deflection of interest, the slight relative variation in $z$ (caused by the surface deformation) will have a negligible effect on the calculation of the direction of the normal vector. At very close range, though, the surface deformation could constitute a larger portion of the $z$ coordinate; thus, if the surface displacement is not known, the process of calculating the surface normal direction becomes recursive and possibly subject to errors.

The greatest benefit of increased range, however, is in magnifying the size of image distortions. Figure 2-5 illustrates this effect. Consider the mirror element canted at a small angle $\varepsilon$ from the nominal mirror plane, which will displace the observed virtual image by twice that amount (or 2E) from its original position $P_{0}$ regardless of the distance of the observer and target from the mirror. To the closer observer $o_{1}$, this is small relative to the apparent size of the mirror. To the more distant observer $\mathrm{O}_{2}$, this shift in the virtual image position is more significant compared with the apparent size of the mirror as viewed from that distance.

Increasing the range if carried too far can make data gathering using pattern recognition difficult or impossible. To illustrate this point, Figure 2-6 shows a situation in which the local radius of the membrane curvature is shorter than the distance to the observer and grid. In this situation, the membrane tension is too low to pull out small ripples in the membrane material. The result is a garbled image that is next to impossible to decipher as it is. Thus, we must select the appropriate range to achieve a good balance between measurement sensitivity and usable curvature range.

A major capability of this method is that each virtual image "snapshot" taken by the observer camera is a complete record of the mirror's shape at that instant. Virtually no time is taken to "scan" the surface, as in laser ray tracing. This makes it possible to study the structural dynamics of the mirror's surface. In addition, the sharpness of the virtual image or, conversely, the amount of blurring of the image's details contains information about the specularity of the mirror's surface. Appendix C discusses surface specularity effects furt:her.

Others have used virtual image techniques to analyze solar reflectors. The Jet Propulsion Laboratory (JPL) tested parabolic dish mirrors with a still camera and a small, colored, concentric ring target located at or near the supposed center of curvature of the mirror (Christ 1984). The measurements indicated the extent that the surface slope varied with respect to a pure spherical shape by observing the extent to which the concentrator's aperture was filled with each color. JPL (Argoud and Dennison 1982) used another approach that is closer to those employed for testing smaller astronomical telescope mirrors. They produced a large, collimated beam using an existing solar simulator. The beam was directed onto the mirror being tested, and a camera recorded the distribution of light that passed through various apertures positioned at its supposed focal point. Researchers used annular apertures corresponding to increasing slope error to gather data on the mirror's shape. 


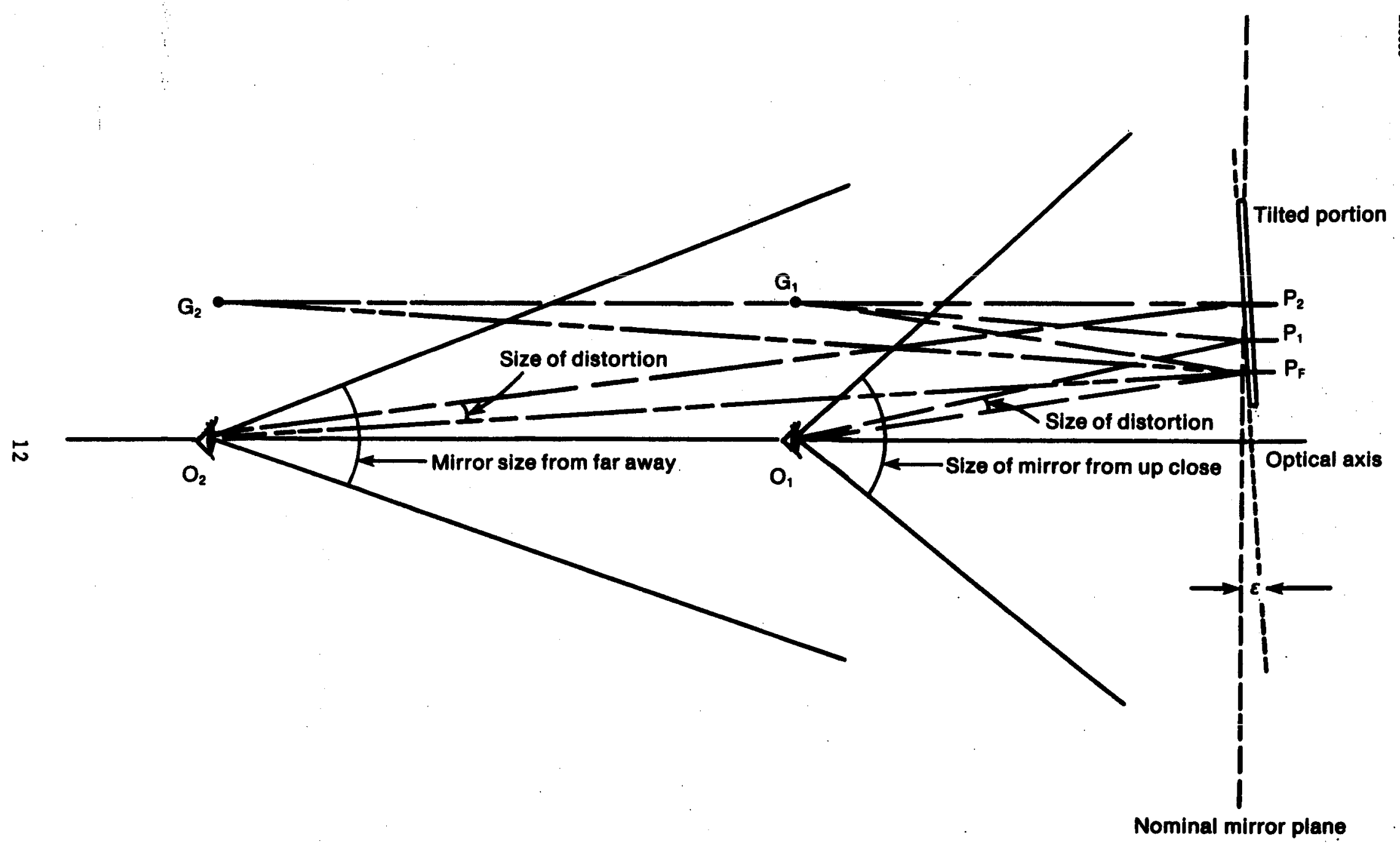

Pigure 2-5. Mirror Distortions Appear Relatively Larger at Greater Distances 
The Lawrence Livermore Laboratory (LLL) developed a test for parabolic troughs that examined the apparent size and location of the virtual image of the receiver pipe itself. To do this they shot many consecutive movie frames as the mirror was scanned past the observer's axis (Wood 1981). If the data are properly treated, this distant observer method will show not only the slope errors in the mirror but the positioning error of the receiver pipe within the trough. An amplification of this method is being planned, which may be used to assess the surface shape of large parabolic dishes now being designed for SNLA.

These three methods directly measure slope errors (relative to some reference), not absolute surface normal direction, as SERI's heliostat test method does. Also, SERI's heliostat test differs markedly from the others because the observed object and the observer lie well inside the radius of curvature of the mirror. The test relies on recognizing and locating individual measuring areas or other sizes. observations to fully characterize error magnitude and direction. They are appropriate for testing the more deeply curved mirrors they were designed for, but SERI's method is more appropriate for the nearly flat heliostats.

\subsection{DATA AMALYSIS}

The virtual image technique yields a self-consistent field of surface normals with a low noise level superimposed by the uncertainties discussed in Appendix C. We are assuming that the bulk of the noise has a Gaussian distribution. We apply the least squares method to deternine a best guess of the mirror's shape. To do this we assume a shape equation (Murphy and Sallis 1984) of the form

$$
\begin{aligned}
z(r, \theta) & =c\left(\frac{r}{a}\right)^{2}-1+\sum_{n=2}^{\infty} A_{n}\left(\frac{r}{a}\right)^{n} \cos (n \theta) \\
& +\sum_{n=2}^{\infty} B_{n}\left(\frac{r}{a}\right)^{n} \sin (n \theta),
\end{aligned}
$$




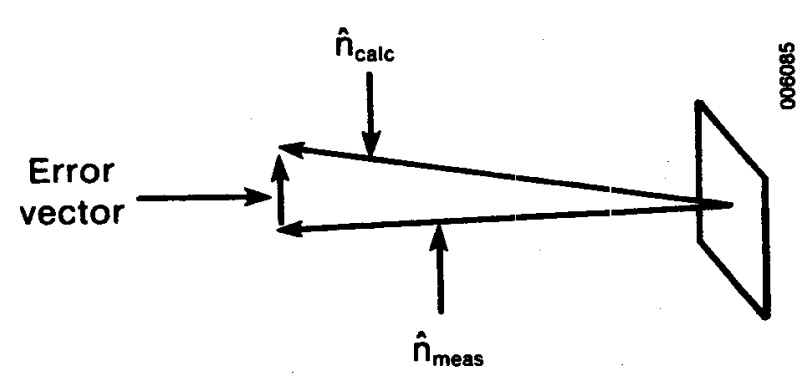

Figure 2-7. Error Vector Definition. Coefficients for the assumed shape equation are chosen to minimize the sum of the squares of the lengths of all the error vectors, the difference between the measured surface normal vectors and those indicated by the equation. where

$$
\begin{aligned}
\mathbf{z}= & \text { displacement of the surface } \\
& \text { toward the observer } \\
\mathbf{r}= & \text { radius } \\
\mathbf{a}= & \text { rim radius } \\
\theta= & \text { circumferential angle measured } \\
& \text { positive counterclockwise }(\theta=0 \\
& \text { at the } 3 \text { o'clock position). }
\end{aligned}
$$

The first term is the axisymmetric dishing caused by a slight pressure difference of an ideal membrane on a planar ring. The Fourier series form in Eq. 2-2 describes the threedimensional shape of a free, ideal membrane on a nonplanar support.

An alternative form for the equation combines the Fourier cosine and sine series in the form

$$
z(r, \theta)=C\left(\frac{r}{a}\right)^{2}-1+\sum_{n=2}^{\infty} D_{n}\left(\frac{r}{a}\right)^{n} \cos n\left(\theta+\phi_{n}\right) .
$$

The term $\phi_{n}$ is thus the angular position of the peak of the corresponding model deflection. A subset of these terms describes the expected shape as predicted by theoretical analysis. The additional terms retained here permit unexpected nonlinear structiral deformation phenomena to be revealed if present.

We can choose the best values for the coefficients $A_{n}, B_{n}$, and $C(n=2,3,4, \ldots)$ by fitting this equation to the surface normal data. For the small slopes we observe (typically less than $15 \mathrm{mrad}$ ) the $r$ and $\theta$ components of the normal vector are almost exactly $d z / d r$ and $1 / r \mathrm{dz} / \mathrm{d} \theta$, which we can obtain by differentiating the assumed shape equation. Next we select values for the As, $B s$, and $C$ that minimize the function:

$$
\begin{aligned}
F & =\sum_{m}\left[\hat{n}_{c a l c}\left(r_{m}, \theta_{m}\right)-\hat{n}_{\text {measured }}\right]^{2} \\
& \approx \sum_{m}\left[\frac{\partial z}{\partial r}\left(r_{m}, \theta_{m}\right)-\left.\frac{\partial z}{\partial r}\right|_{m}\right]^{2}+\sum_{m} \frac{1}{r_{m}^{2}}\left[\frac{\partial z}{\partial \theta}\left(r_{m}, \theta_{m}\right)-\left.\frac{\partial z}{\partial \theta}\right|_{m}\right]^{2},
\end{aligned}
$$

which is the sum of the squares of the magnitudes of all the error vectors, the difference between the measured surface normal direction $\hat{n}_{\text {measured, and }}$ the normal direction indicated by the assumed Eq. 2-1 and as defined in Figure 2-7. Since the terms in Eq. 2-1 are linear in $A_{n}, B_{n}$, and $C$, i.e., no products of As, Bs, or $C$ exist, the best values for the coefficients can be found in closed form as in least squares polynomial fitting. However, we chose to apply a general searching routine to find the minimum so we could have studied nonlinear terms if the data had so indicated. 
In almost all cases the data were fit to curves with a residual RMS error $(\sqrt{F / m})$ of about $1.0 \mathrm{mrad}$, which is about the amount expected with all of the noise sources considered. None of the fits had an RMS error of over $1.5 \mathrm{mrad}$, which suggests that the assumed equation was indeed a good choice and fit the phenomena very well. 
SECTIOX 3.0

\section{FIMDINGS}

We conducted six series of tests on the four mirror modules described earlier: three pneumatically attached modules with their weight suspended at the bottom support, two pneumatically attached modules with their weight suspended from the upper mounts, and one rigidly attached module with its weight suspended at the bottom mount (see Table 2-1). The reduced data are given in Appendix A.

Overall, there were few surprises in the results. The most significant finding was that, as predicted, the measured amplitudes corresponding to three terms from the assumed deflection equation (Eq. 2-2), the $n=0$ term (axisymmetric dishing), the $n=2$ term (frame imperfections), and the $n=3$ term were the only ones of any significance. A pure $n=2$ deflected module has two high points and two low points on the rim, a shape resembling a potato chip. An $n=3$ deflection has three regularly spaced high points and three low points, but the shape otherwise is similar to the potato chip saddle.

The $\mathbf{n}=2$ mode arises for the initial imperfections and is present in all cases to some extent. Loading on the module can greatly amplify this mode if it is not constrained by the supports. On the other hand, if more than three supports are used, we can probably eliminate this mode of deformation or mitigate it to negligible levels.

The $n=3$ mode arises from the three supports; $i . e .$, since the frame is rigidly supported normal to the membrane's plane at just three points, it tends to deflect between the supports. Analogously, there will always be a corresponding deformation mode corresponding to the number of supports (for any number). The data show that the $n=2$ and $n=3$ deflection modes can and do coexist for the three-support configuration.

In these experiments we found that all the coefficients corresponding to the higher order modes of deformation were insignificant. We carefully analyzed the data in search of harmonics up to $n=12$ with no success. If these harmonics are present, they are too small for this system to measure.

\subsection{AMPLIFICATION OF IMITIAL IMPERPECTIONS- $n=2$ DEFORMATION}

As expected, as we increased the membrane tension with no external pressure load, the $n=2$ deflection increased. In two exceptional cases, mirrors 1 and 2 with bottom support, the intermediate tension caused a larger $n=2$ deflection. However, it is likely that these modules were plastically strained during the high-tension series that preceded the intermediate-tension tests. The low-tension and high-tension, low-external-load tests, which were done before the expected overload, are consistent with the predictions (see Figure $A^{-1}$ in Appendix $A$ ). 
In the low- and intermediate-membrane-tension cases, the $n=2$ deflection depended very little on the simulated wind load (see Figure $A-1$ in Appendix A). One of the exceptions was in series M03B (mirror 3, bottom supported). This mirror module had the largest initial $n=2$ imperfection of the three ring frames. The fabricator had warned us that this ring was very flat when sitting free but that there were more twists and discontinuities in the cross-section than on the first and second ring. With its membrane under tension, the ring's nonuniformities caused the marked potato chip. As the wind load was increased, the magnitude of this module's $n=2$ deflection actually decreased. Thus, the simulated wind load tended to flatten the ring frame, perhaps because of the way the ring frame imperfections are positioned relative to the support points.

On mirrors one and two, the high-membrane-tension cases show an increase of the $\mathrm{n}=2$ deflection with increasing simulated wind loading. With mirror three, which had a markedly higher initial $n=2$ deflection, the $n=2$ deflection decreased with increasing load in the low-load range. Again, the ring frames in all of the high-tension cases were very close to buckling and may have been plastically deformed. This is the probable cause of any inconsistency between the low and intermediate tension test results. (We were unaware of this during testing, since the $n=2$ and $n=3$ ring deflections are hard to recognize visually. The principal visual effect of wind loading is the marked magnification of the virtual image because the membrane dishes axi symmetrically.)

The direction or orientation of the $\mathfrak{n}=2$ deflection varied somewhat with load on all tests. Even tests that showed very little amplification of the $n=2$ deformation mode with load showed some orientation shift (see Figure A-2 in Appendix A). There are not enough data to be conclusive, but the shift appears to align one of the $n=2$ valleys with one of the $n=3$ valleys. (In the figure, the MO2B curves appear to be approaching an $n=3$ peak. On the far side of the ring, the other $n=2$ valley is approaching an $n=3$ valley.) This is consistent with a possible nonlinear coupling between membrane dishing, out-of-plane buckling, and in-plane deformation of the frame. This coupling problem is discussed in a forthcoming publication (Murphy, Sallis, and simms) that describes the postbuckling response of a specific module.

\subsection{SUPPORT-IMDUCED $\mathrm{n}=3$ DEFLECTIOY}

The $\mathrm{n}=3$ deflections were considerably better behaved as anticipated. The orientation always showed the $n=3$ peaks to lie directly over the supports. The magnitudes, however, were sometimes considerably higher than expected. In Figures A-4 through A-7 in Appendix A, deflections are plotted as a function of membrane tension and wind load for all of the pneumatically attached tests. The values plotted are not the gross $n=3$ coefficient determined for the test but are the difference between the loaded and unloaded condition, since some initial deformation corresponding to the $n=3$ mode typically existed in each unloaded case. The curves shown are theoretically predicted deflections for an ideal single membrane module with a spring attachment and uniform loads normal to the plane of the membrane. Further, the model, as 
described in detail in Murphy (1985), does not consider in-plane weight effects, twisting or bending moments induced by the supports, the rim sealing loads, nor the full effect of the pneumatic attachment.

The largest differences between measured and predicted deformations seem to occur in the lower tension cases, while agreement seems to be very good in the high-tension, lowvacuum cases. (As mentioned before, the high-tension, high-vacuum cases were probably too near the buckling load.) Furthermore, we suspect that the vacuum seal between the mirror module and the loading fixture may have added appreciably to the deflecting load despite the provisions against it.

This notion is supported since the data for mirror 2 fit the predicted curves very well, especially at the lower tensions, while mirrors 3 and 1 are progressively farther off. The mirrors were tested in $2,3,1$ order. For the mirror 2 tests, the seal was not working because of insufficient sealing force; we used masking tape to seal the mirror to the loading fixture. Before testing mirror 3 , we modified the seal so the tape would not be necessary. The fixture face plate was bent so the foam rubber seal pressed more firmly against the mirror's rim. The internal support meant to carry the vacuum load on the face plate probably acted as a fulcrum, so increasing the deflection of the face plate caused by internal vacuum tended to lift the seal away from the mirror's rim, reducing the systematic load on it (see Figure 3-1).

Nonetheless, the deflections are not unreasonable. They are well within an acceptable error allowance, considering all of the assumptions in the analytical models, the

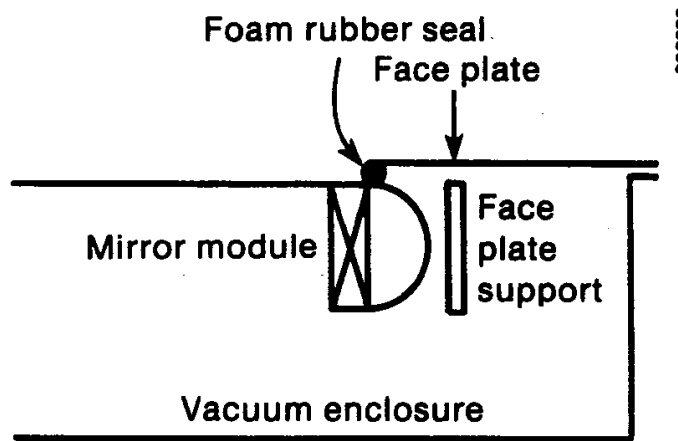

(a)
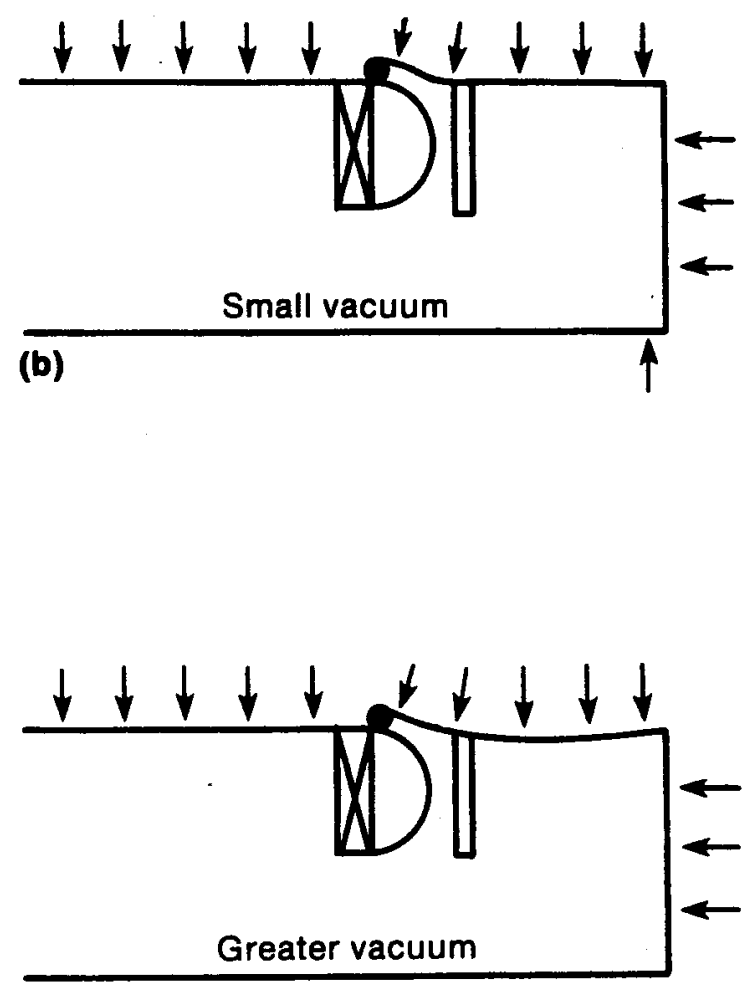

(c)

Figure 3-1. Wind Load Simulator Rim seal. The sealing force of the sponge rubber seal on the mirror's rim may have contributed an appreciable out-of-plane bending force to that rim. Deflection of the face plate at higher vacuum may have served to unload the rim. 
controllable and uncontrollable errors in the experimental method, and perverse factors. In 36 tests on hardware of similar configuration the measured deflection averaged $17 \%$ higher than the predicted deflection. If we take into account the additional force that the rim seal of the loading fixture imposed on the module frame, these errors would have been significantly smaller. In particular, the mirror 2 data that were taken with the superior rim seal agree with the predictions within a few percentage points ( $<6 \%$ RMS).

The data obtained on module 4 (which is actually the same membrane and frame as the original module 2 but with the rigid adhesive bond between the membrane and frame) are inconclusive. Predictions were that the rigid attachment would make the module somewhat stiffer to external loading.* We tested the module with two different membrane tensions. At high tension the rigidly attached module did not increase in stiffness compared with the pneumatically attached module 2. Reworking and rebonding it at a lower tension caused a much larger initial $n=2$ and $n=3$ deformation. This module now showed a much higher amplification of the $n=3$ deflection with increasing load than had any of the pneumatically attached modules. The fabricator had warned us that the membrane sustained much damage when they removed the first bond and made the second, lower tension bond. Something may have gone wrong with it during rework or during shipping. In any event, not much can be said about these last findings.

*A much larger stiffening effect is associated with a double-membrane design, since the membranes behave analogously to flanges on the frame when we consider out-of-plane bending. In single-membrane designs, the roll of the frame cancels part of this benefit (roll is greatly restrained with doublemembrane designs). 
TR-2736

\section{SECrIOX 4.0}

\section{CONCLUSIONS AND RECOMERDATIONS}

Based on test results of the single-membrane modules using three supports described in this report, we reached the following conclusions:

- The dominant module response observed in the tests is consistent with prior analysis findings derived from a simple analytical model and from the far more detailed NASTRAN finite element analysis studies of larger modules.

- Measured membrane and frame deformations induced by the pressure loading and the periodic support constraints averaged within $17 \%$ of the predicted values when the simple analysis method was used, even though idealized support conditions varied significantly from the true conditions. This agreement with predictions is even more encouraging since we believe that the experimental errors (such as the unanticipated force imposed on the edge by the rim seal) can account for most of the largest errors seen that occurred with mirror modules 1 and 3 .

- The simple analytical model is quite adequate for designing and sizing single-membrane modules if the initial imperfections and their amplification are appropriately controlled.

- We found that initial imperfections corresponding to the primary $n=2$ deformation mode can be quite important. Note, however, the overly flexible frame design intentionally exaggerated the effects seen in these tests relative to realistic practical designs. Further, the $n=2$ load deformation response is quite complex, as the more detailed NASTRAN analysis of larger modules confirmed. More specifically, the tests confirmed that coupling may occur that involves axisymmetric dishing $(n=0)$ as well as the $n=2$ and $n=3$ deflection modes, because the $n=2$ deflection reorients itself under pressure load so one of its valleys falls atop one of the $n=3$ valleys. Some cases show an associated amplification of the $n=2$ magnitude, and others, where the initial $n=2$ magnitude was large, show that it was attenuated by load. The prior NASTRAN computer code analysis showed that a nonlinear coupling occurs between the in-plane frame deformation and the out-of-plane $n=2$ deformation modes. This coupling increases dramatically when a pressure load is placed on the membrane and the membrane tension load is simultaneously near or above the out-of-plane buckling load for the frame only (no membrane restoring force). Furthermore, by appropriately placing the initial imperfection pattern on the support points, we would anticipate that in some cases the frame membrane combination would be flattened relative to the initial configuration, though this was not studied or predicted in the earlier analyses.

- To avoid potential problems resulting from the fundamental $n=2$ deformation phenomena, we advise using either relatively stiffer ring frames or more than three support points on the ring frame. Using more than three supports makes it possible to remove most or all of the $n=2$ deformation and its subsequent amplification. 
- We failed to see any significant differences between the rigidly bounded and hydraulically attached single-membrane designs. The anticipated difference based on analogies with NASTRAN results for larger configurations is small (within the experimental error limitations). We still anticipate that rigid bonds will significantly affect the doublemembrane designs.

We will soon be testing a rigidly bonded, two-membrane module, one with a second membrane on the back of the ring as well. The structural features and advantages of this scheme are discussed in Murphy and Sallis (1984), Murphy (1985), and Murphy, Sallis, and Simms (forthcoming). We will eliminate the systematic errors uncovered in these tests, primarily relating to extraneous loads, from the upcoming tests.

If more tests on single-membrane structures are called for later, it would be relatively inexpensive and perhaps enlightening to reexamine module 1 now that we know more about what to look for. (Mirror 2 is now mirror 4 and may not be recoverable. Mirror 3 was damaged while being made into a laminated-membrane module.) However, considering the current DOE emphasis on the two- membrane design for heliostats, future tests on single-membrane modules are unlikely.

Upcoming SERI research of wind-excited vibration modes of the stretched membrane structure will use this virtual image method to quantify the drumhead and transverse wave modes of membrane oscillations. In this application we will make high-speed motion pictures of the virtual image field using a 2-ft-diameter model in a wind tunnel. Each movie frame will be studied separately to quantify the membrane displacement, and the sequence will then be reconstructed to obtain membrane displacement as a function of time.

An in-the-field version of this test is feasible if we modify the hardware. For relatively flat mirrors (where the curvature radius is much longer than the distance between observer and the mirror), the checkerboard grid must be nominally twice the mirror diameter if we want to fill the entire mirror with the grid image. Testing mirrors any bigger than 3 meters using this method would be quite an undertaking, and such tests in the field would be extremely unwieldy at best. A good compromise may be found in a one-dimensional target (pole with alternating color bands) with scanning of the mirror in the other axia. We could obtain similar results using this hardware modification, although it would involve more data collection and reduction. 


\section{SECTIOU 5.0}

\section{REFEREACES}

Argoud, M. J., and E. W. Dennison, 1982, Optical Characterization of Solar Concentrator Mirrors Using the Solar Beam of the JPL 25-foot Space Simulator, NASA N-82-25296, Pasadena, CA: Jet Propulsion Laboratory.

Christ, G. R., AAI Corp., 1984, "Determining the Slope Error of a Parabolic Reflector," NASA Tech Briefs, p. 484.

Murphy, L. M., 1983 (May), Technical and Cost Benefits of Lightweight, Stretched-Membrane Heliostats, SERI/TR-253-1818, Golden, CO: Solar Energy Research Institute.

Murphy, L. M., and D. V. Sallis, 1984 (May), Analytical Modeling and Structural Response of a Stretched Membrane Reflective Module, SERI/TR-2532101, Golden, Co: Solar Energy Research Institute.

Murphy, L. M., 1985 (Oct.), A Variational Approach for Predicting the Load Deformation Response of a Double Stretched Membrane Reflector Module SERI/TR-252-2626, Golden, CO: Solar Energy Research Institute.

Murphy, L. M., D. V. Sallis, and D. Simms, forthcoming, Structural Design Considerations for Stretched Membrane Heliostat Reflector Modules with Stability and Initial Imperfection Considerations, SERT/TR-253-2338, Golden, Co: Solar Energy Research Institute.

Wood, R. L., 1981, Distant Observer Techniques for Verification of Solar Concentrator Optical Geometry, UCRL-53220, Livermore, CA: Lawrence Livermore National Laboratory. 


\section{APPEADIX A}

\section{TEST RESULTS}

The reduced data from all of the tests performed on the Dan-Ka Products 3 meter diameter, single stretched-membrane mirror modules is presented here. Table A-1 gives the axisymetric dish coefficient and the Fourier coefficients and phase angles obtained when the assumed equation (shown in the table) is fit to the various sets of surface slope data. The slope data were obtained by analysis of the video/digitized virtual images according to the method described elsewhere in this report. Figures A-1 through A-7 show the dependence of the indicated deflection amplitudes on important loading variables. Figures A-8 through A-12 illustrate, qualitatively, the interpretation of the virtusl image data. 
Table A-1. Apparent Membrane Shape from Curve Fit to Slope Data

The assumed shape equation is

$$
Z(r, \theta)=c\left[\left(\frac{r}{a}\right)^{2}-1\right]+\sum_{n=2}^{\infty} A_{n}\left(\frac{r}{a}\right)^{n} \cos n\left(\theta-\phi_{n}\right) .
$$

Key to test name mNNxBBBsVVV:

mNN module number

$x$ differentiation between the different multiple pictures made for that condition

BBB pressure in tensioning bladder (in tenths of psi)

$s$ weight support position

b bottom bracket

$t$ upper two brackets

VVV uniform vacuum load behind the membrane (in hundredths of inches of water).

Coefficients are in millimeters; $\theta$ in degrees.

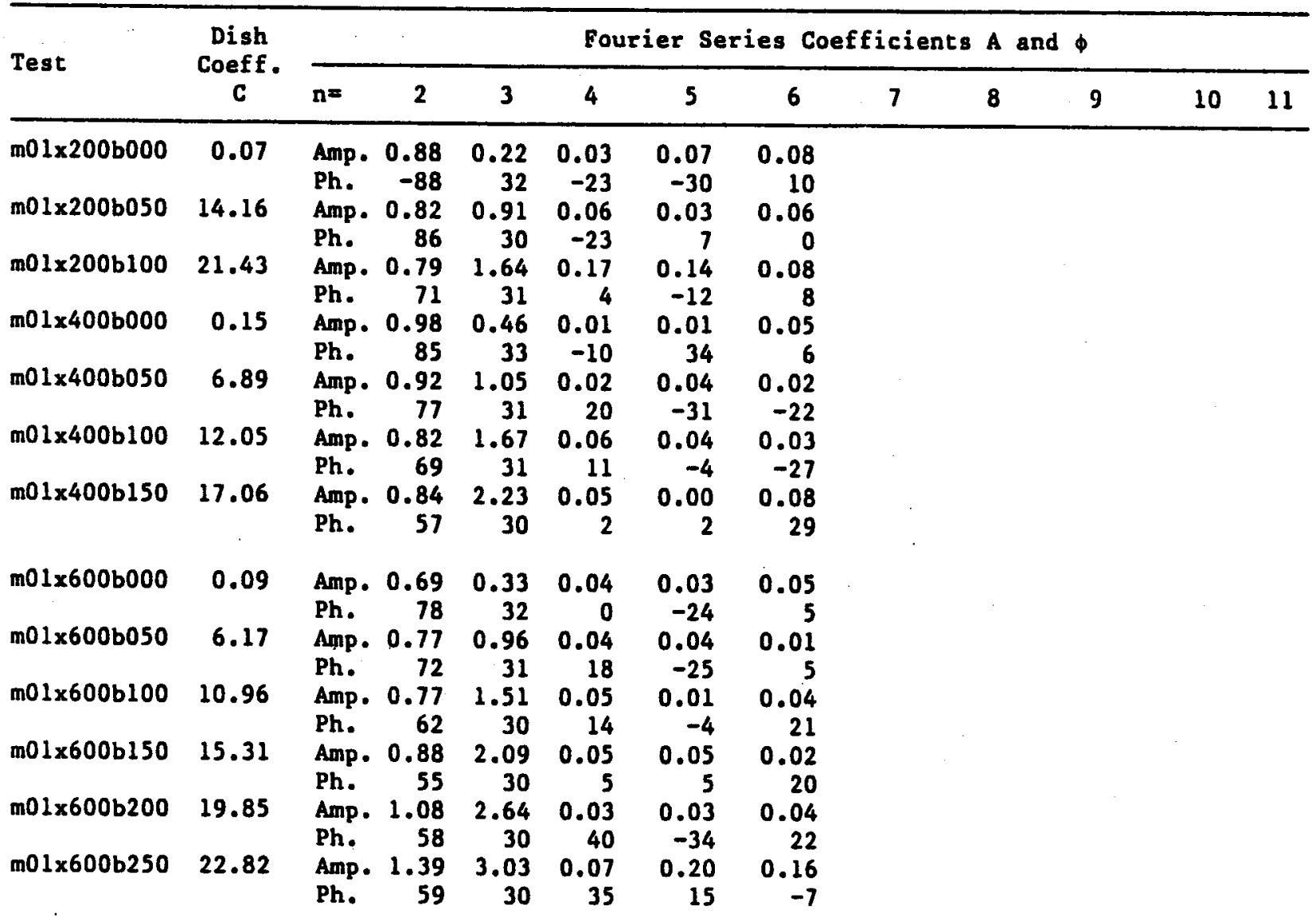


Table A-1. Apparent Membrane Shape from Curve Fit to Slope Data (Continued)

\begin{tabular}{|c|c|c|c|c|c|c|c|c|c|c|c|c|}
\hline \multirow{2}{*}{ Test } & \multirow{2}{*}{$\begin{array}{c}\text { Dish } \\
\text { Coef. } \\
\text { C }\end{array}$} & \multicolumn{11}{|c|}{ Fourier Series Coefficients $A$ and $\phi$} \\
\hline & & $n=$ & 2 & 3 & 4 & 5 & 6 & 7 & 8 & 9 & 10 & 11 \\
\hline $\begin{array}{l}\mathrm{m} 01 \times 400 t 000 \\
\mathrm{m01} \times 400 t 050 \\
\mathrm{~m} 01 \times 400 \mathrm{t} 100 \\
\mathrm{~m} 01 \times 400 \mathrm{t} 150\end{array}$ & $\begin{array}{r}0.29 \\
7.22 \\
12.61 \\
17.35\end{array}$ & $\begin{array}{l}\text { Amp. } \\
\text { Ph. } \\
\text { Amp. } \\
\text { Ph. } \\
\text { Amp. } \\
\text { Ph. } \\
\text { Amp. } \\
\text { Ph. }\end{array}$ & $\begin{array}{r}1.62 \\
68 \\
1.60 \\
71 \\
1.58 \\
65 \\
1.74 \\
59\end{array}$ & $\begin{array}{r}0.68 \\
33 \\
1.25 \\
31 \\
1.74 \\
31 \\
2.37 \\
30\end{array}$ & $\begin{array}{r}0.02 \\
-22 \\
0.02 \\
20 \\
0.06 \\
11 \\
0.11 \\
31\end{array}$ & $\begin{array}{r}0.01 \\
-14 \\
0.03 \\
-16 \\
0.02 \\
30 \\
0.10 \\
-19\end{array}$ & $\begin{array}{r}0.08 \\
7 \\
0.01 \\
0 \\
0.03 \\
-27 \\
0.07 \\
-12\end{array}$ & & & & & \\
\hline $\begin{array}{l}m 02 \times 150 b 000 \\
m 02 \times 150 b 050\end{array}$ & $\begin{array}{r}0.24 \\
16.39\end{array}$ & $\begin{array}{l}\text { Amp. } \\
\text { Ph. } \\
\text { Amp. } \\
\text { Ph. }\end{array}$ & $\begin{array}{r}0.27 \\
-42 \\
0.37 \\
-40\end{array}$ & $\begin{array}{r}0.06 \\
26 \\
0.71 \\
29\end{array}$ & $\begin{array}{r}0.03 \\
19 \\
0.06 \\
36\end{array}$ & $\begin{array}{r}0.02 \\
-35 \\
0.08 \\
-30\end{array}$ & $\begin{array}{r}0.06 \\
10 \\
0.02 \\
3\end{array}$ & & & & & \\
\hline $\begin{array}{c}\text { m02x350b000 } \\
\text { m02x350b050 } \\
\text { same } \\
\text { same } \\
\text { same }\end{array}$ & $\begin{array}{c}0.33 \\
7.71 \\
11 \\
11 \\
11\end{array}$ & $\begin{array}{l}\text { Amp. } \\
\text { Ph. } \\
\text { Amp. } \\
\text { Ph. } \\
\text { Amp. } \\
\text { Ph. } \\
\text { Amp. } \\
\text { Ph. } \\
\text { Amp. } \\
\text { Ph. }\end{array}$ & $\begin{array}{l}0.55 \\
-42 \\
0.54 \\
-47 \\
0.55 \\
-47 \\
0.55 \\
-47 \\
0.55 \\
-47\end{array}$ & $\begin{array}{r}0.18 \\
33 \\
0.63 \\
30 \\
0.63 \\
30 \\
0.63 \\
30 \\
0.63 \\
30\end{array}$ & $\begin{array}{r}0.05 \\
29 \\
0.09 \\
29 \\
0.10 \\
28 \\
0.10 \\
28 \\
0.10 \\
29\end{array}$ & $\begin{array}{r}0.02 \\
-31 \\
0.02 \\
-22 \\
0.03 \\
-27 \\
0.03 \\
-26 \\
0.03 \\
-26\end{array}$ & $\begin{array}{r}0.06 \\
11 \\
0.03 \\
8 \\
0.03 \\
6 \\
0.03 \\
5 \\
0.03 \\
5\end{array}$ & $\begin{array}{r}0.03 \\
-2 \\
0.03 \\
-2 \\
0.03 \\
-1\end{array}$ & $\begin{array}{r}0.03 \\
14 \\
0.04 \\
14 \\
0.04 \\
14\end{array}$ & $\begin{array}{r}0.04 \\
-19 \\
0.04 \\
-19 \\
0.04 \\
-18\end{array}$ & $\begin{array}{r}0.01 \\
2 \\
0.01 \\
-2\end{array}$ & $\begin{array}{r}0.01 \\
11\end{array}$ \\
\hline $\begin{array}{l}\mathrm{m02} \times 350 \mathrm{~b} 100 \\
\mathrm{m02} \times 350 \mathrm{~b} 150\end{array}$ & $\begin{array}{l}13.86 \\
19.30\end{array}$ & $\begin{array}{l}\text { Amp. } \\
\text { Ph. } \\
\text { Amp. } \\
\text { Ph. }\end{array}$ & $\begin{array}{l}0.63 \\
-59 \\
0.70 \\
-65\end{array}$ & $\begin{array}{r}1.05 \\
30 \\
1.64 \\
30\end{array}$ & $\begin{array}{r}0.11 \\
34 \\
0.11 \\
45\end{array}$ & $\begin{array}{r}0.04 \\
13 \\
0.10 \\
-23\end{array}$ & $\begin{array}{r}0.02 \\
15 \\
0.07 \\
-5\end{array}$ & & & & & \\
\hline $\begin{array}{l}m 02 \times 588 b 000 \\
m 02 \times 588 b 050 \\
m 02 \times 588 b 100\end{array}$ & $\begin{array}{r}0.28 \\
6.18 \\
10.96\end{array}$ & $\begin{array}{l}\text { Amp. } \\
\text { Ph. } \\
\text { Amp. } \\
\text { Ph. } \\
\text { Amp. } \\
\text { Ph. }\end{array}$ & $\begin{array}{r}0.44 \\
-34 \\
0.43 \\
-48 \\
0.55 \\
-63\end{array}$ & $\begin{array}{r}0.08 \\
38 \\
0.63 \\
30 \\
1.10 \\
30\end{array}$ & $\begin{array}{r}0.07 \\
29 \\
0.11 \\
33 \\
0.06 \\
35\end{array}$ & $\begin{array}{r}0.02 \\
24 \\
0.05 \\
-10 \\
0.04 \\
-22\end{array}$ & $\begin{array}{r}0.04 \\
10 \\
0.08 \\
11 \\
0.07 \\
14\end{array}$ & & & & & \\
\hline $\begin{array}{l}m 02 \times 350 t 000 \\
m 02 \times 350 t 050 \\
m 02 \times 350 t 100 \\
m 02 \times 350 t 150\end{array}$ & $\begin{array}{r}0.25 \\
8.23 \\
14.39 \\
19.73\end{array}$ & $\begin{array}{l}\text { Amp. } \\
\text { Ph. } \\
\text { Amp. } \\
\text { Ph. } \\
\text { Amp. } \\
\text { Ph. } \\
\text { Amp. } \\
\text { Ph. }\end{array}$ & $\begin{array}{r}0.56 \\
68 \\
0.62 \\
73 \\
0.73 \\
74 \\
0.90 \\
76\end{array}$ & $\begin{array}{r}0.29 \\
31 \\
0.77 \\
30 \\
1.11 \\
30 \\
1.66 \\
30\end{array}$ & $\begin{array}{r}0.07 \\
34 \\
0.06 \\
34 \\
0.06 \\
31 \\
0.18 \\
44\end{array}$ & $\begin{array}{r}0.03 \\
-32 \\
0.03 \\
-26 \\
0.05 \\
8 \\
0.08 \\
-19\end{array}$ & $\begin{array}{r}0.06 \\
9 \\
0.03 \\
19 \\
0.01 \\
16 \\
0.04 \\
24\end{array}$ & & & & & \\
\hline
\end{tabular}


TR-2736

Table A-1. Apparent Membrane Shape from Curve Fit to S1ope Data (Continued)

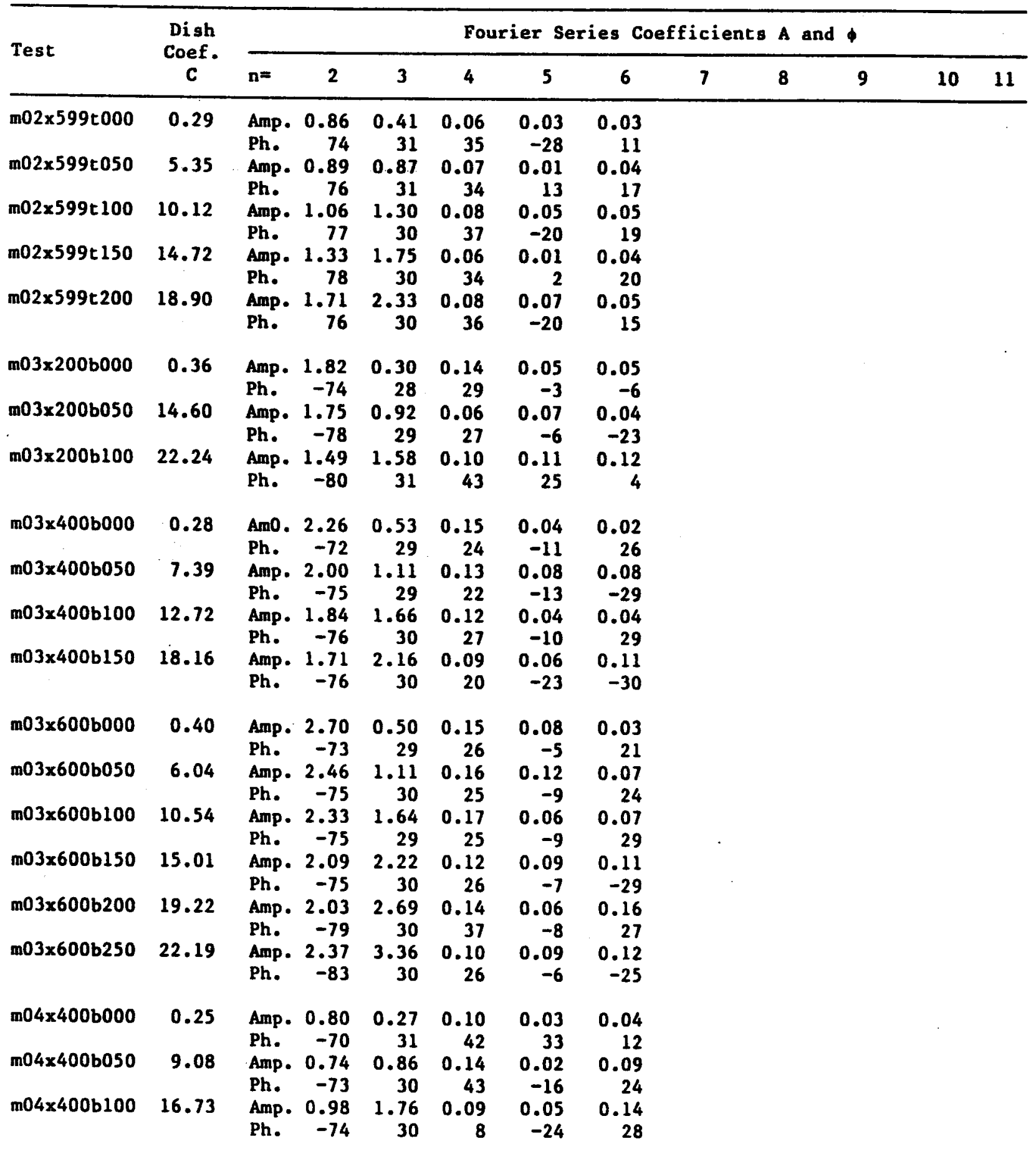


Table A-1. Apparent Membrane Shape from Curve Fitt to Slope Data (Concluded)

\begin{tabular}{|c|c|c|c|c|c|c|c|c|c|c|c|c|}
\hline \multirow{2}{*}{ Test } & \multirow{2}{*}{$\begin{array}{c}\text { Dish } \\
\text { Coef. } \\
\text { C }\end{array}$} & \multicolumn{11}{|c|}{ Fourier Series Coefficients $A$ and } \\
\hline & & $\mathrm{n}=$ & 2 & 3 & 4 & 5 & 6 & 7 & 8 & 9 & 10 & 11 \\
\hline $\begin{array}{l}m 04 \times 400 \mathrm{~b} 150 \\
m 04 \times 600 \mathrm{~b} 000 \\
m 04 \times 600 \mathrm{~b} 050 \\
m 04 \times 600 \mathrm{~b} 100 \\
m 04 \times 600 \mathrm{~b} 150 \\
\mathrm{~m} 04 \times 600 \mathrm{~b} 200\end{array}$ & $\begin{array}{r}21.41 \\
0.24 \\
5.87 \\
10.72 \\
15.15 \\
19.07\end{array}$ & $\begin{array}{l}\text { Amp. } \\
\text { Ph. } \\
\text { Amp. } \\
\text { Ph. } \\
\text { Amp. } \\
\text { Ph. } \\
\text { Amp. } \\
\text { Ph. } \\
\text { Amp. } \\
\text { Ph. } \\
\text { Amp. } \\
\text { Ph. }\end{array}$ & $\begin{array}{r}0.36 \\
-78 \\
0.40 \\
-43 \\
0.52 \\
-62 \\
0.86 \\
-69 \\
1.12 \\
-76 \\
1.37 \\
-78\end{array}$ & $\begin{array}{r}2.15 \\
31 \\
0.19 \\
34 \\
0.75 \\
31 \\
1.22 \\
31 \\
1.66 \\
30 \\
2.15 \\
31\end{array}$ & $\begin{array}{r}0.16 \\
45 \\
0.08 \\
37 \\
0.04 \\
40 \\
0.06 \\
29 \\
0.01 \\
-42 \\
0.10 \\
-9\end{array}$ & $\begin{array}{r}0.04 \\
-21 \\
0.01 \\
-12 \\
0.03 \\
-26 \\
0.01 \\
15 \\
0.02 \\
-30 \\
0.07 \\
-35\end{array}$ & $\begin{array}{r}0.11 \\
10 \\
0.05 \\
15 \\
0.05 \\
18 \\
0.04 \\
23 \\
0.09 \\
14 \\
0.18 \\
17\end{array}$ & & & & & \\
\hline
\end{tabular}




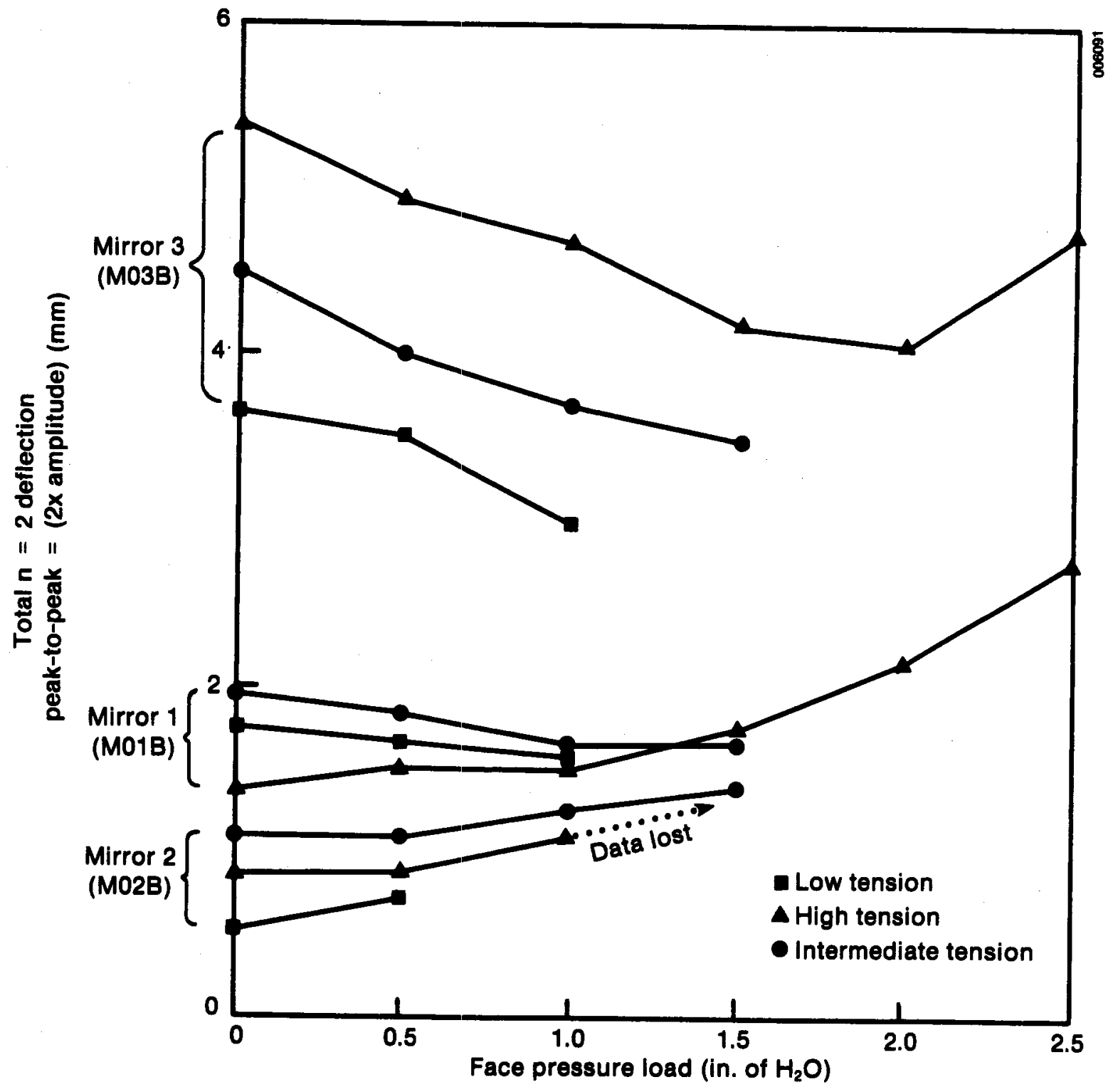

Figure A-1. Amplitude of Primary Mode $(n=2)$ Deflection Component in WindLoaded, Single-Membrane Modules 


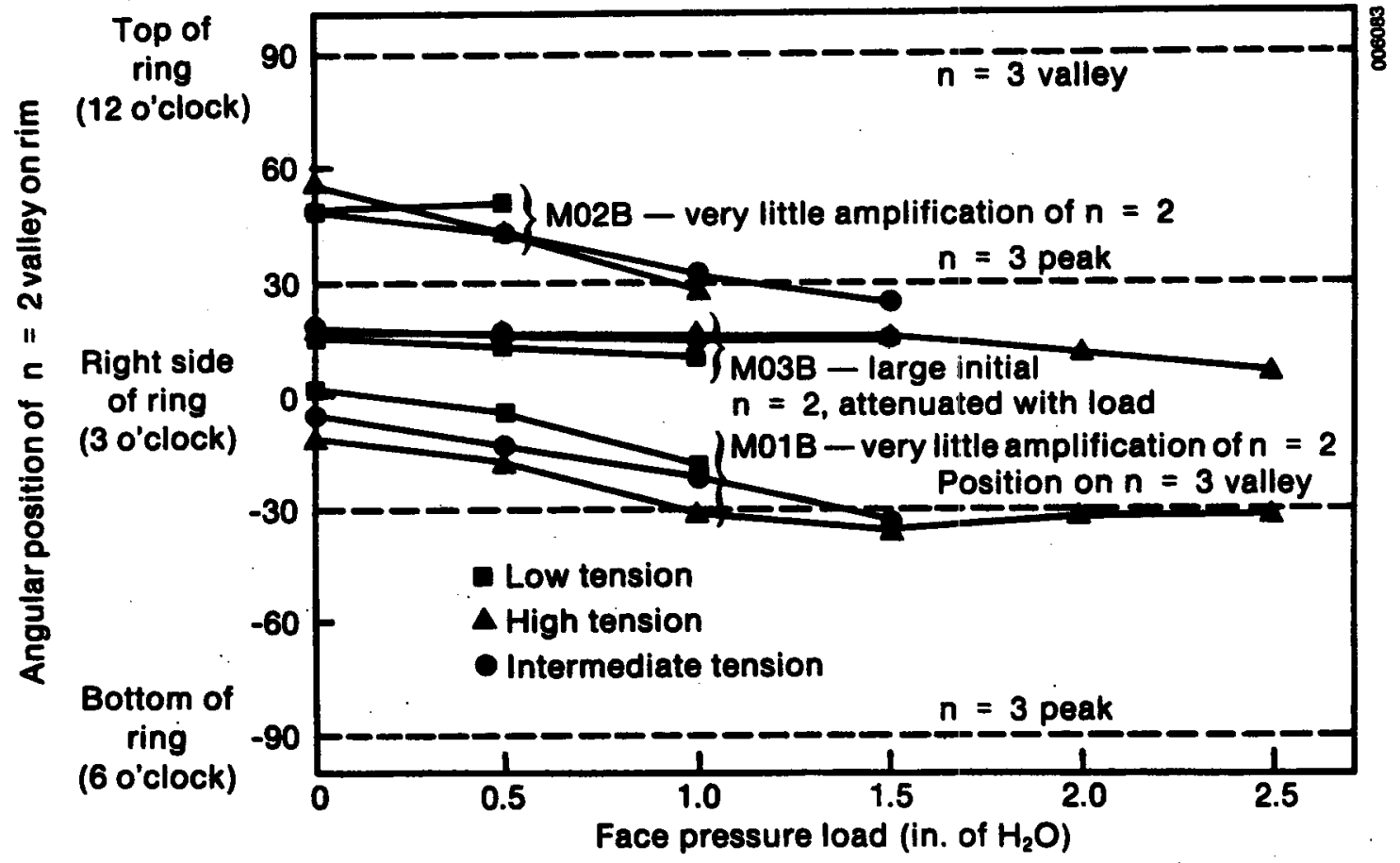

Figure A-2. Orientation of Prinary Hode $(n=2)$ Defilection Component in WindLoaded, Single-Menbrane Modules, Weight: Support at Botton

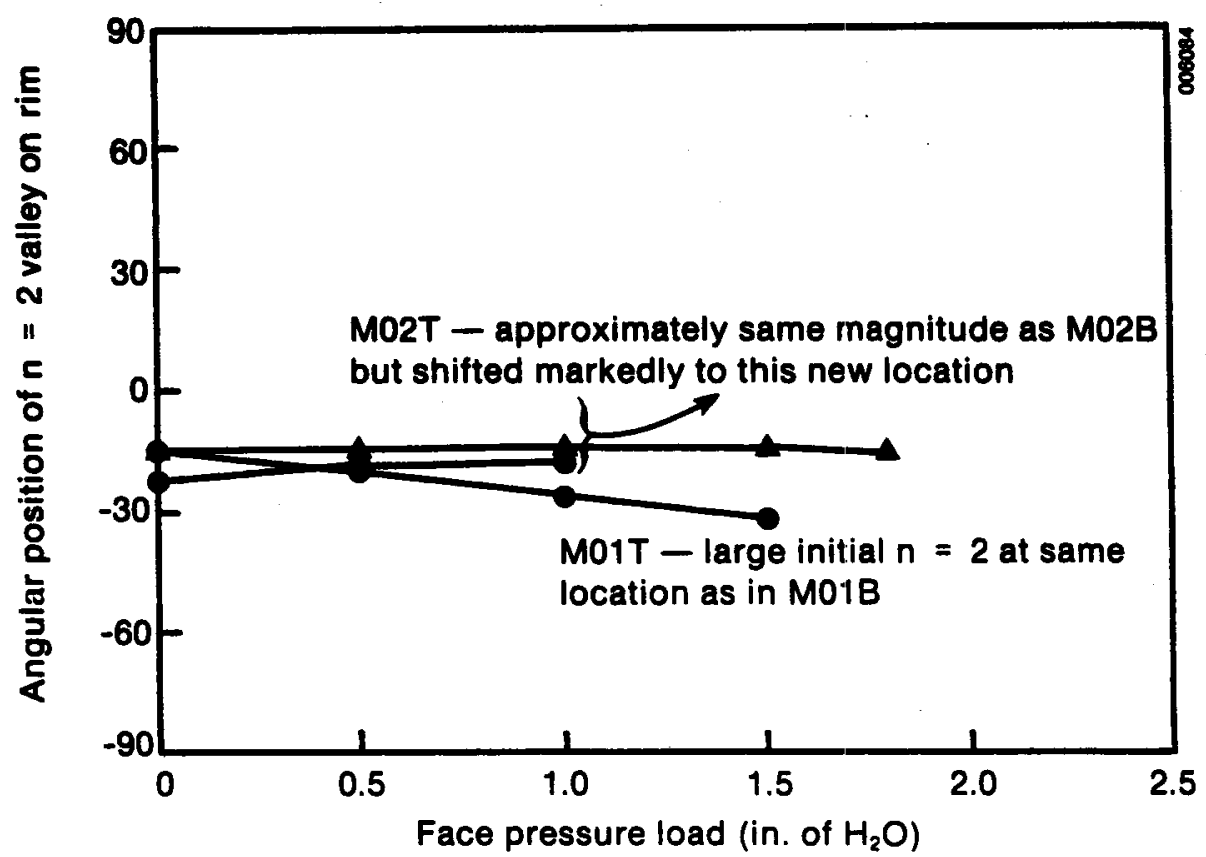

Figure A-3. Orientation of Primary Mode $(n=2)$ Deflection Component in WindLoaded, Single-Membrane Modules, Weight Support at Upper Brackets 


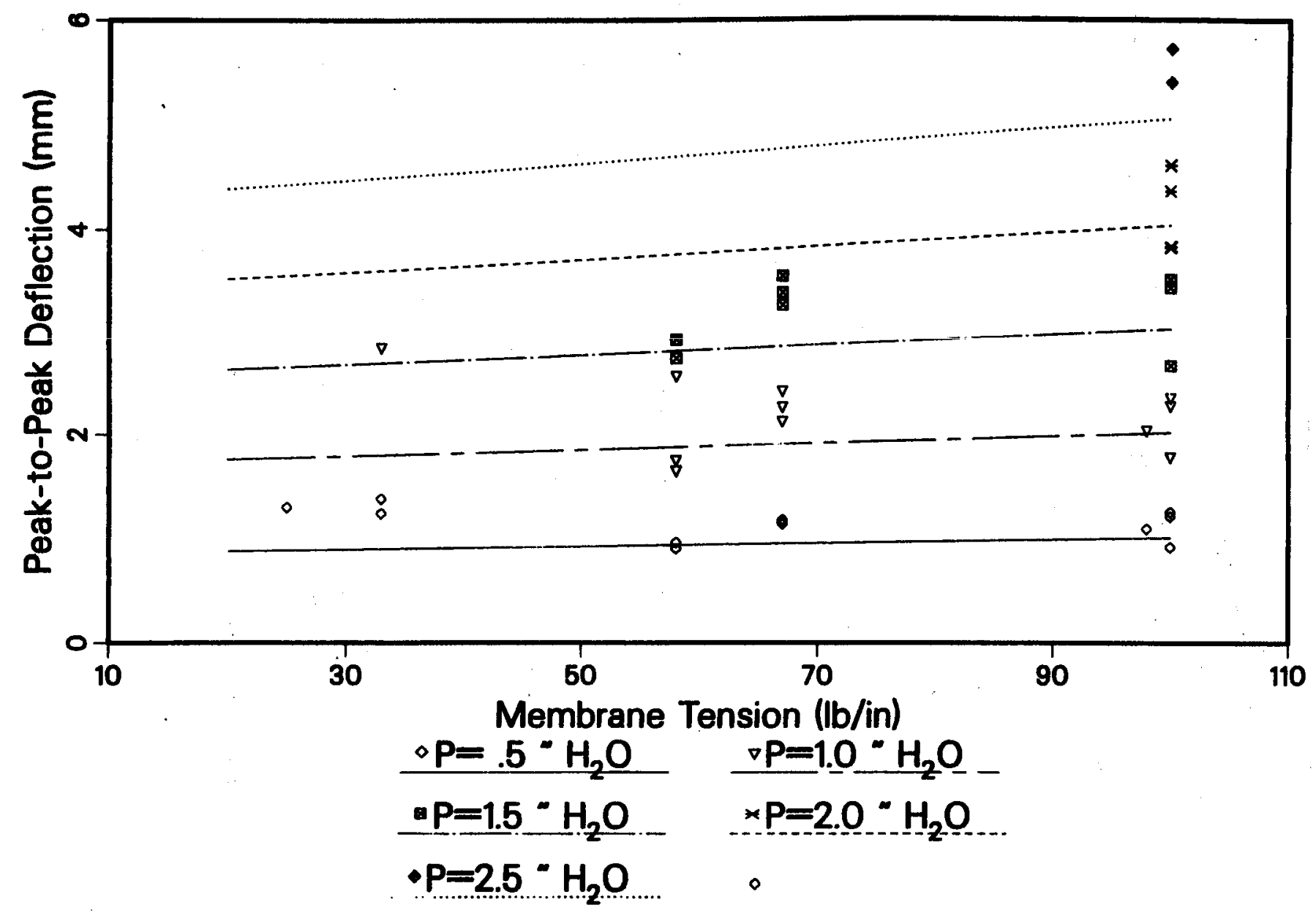

Figure A-4. Peak-to-Peak Magnitude $(=2 \times$ amplitude) of Support-Induced $(n=3)$ Deflection Component 


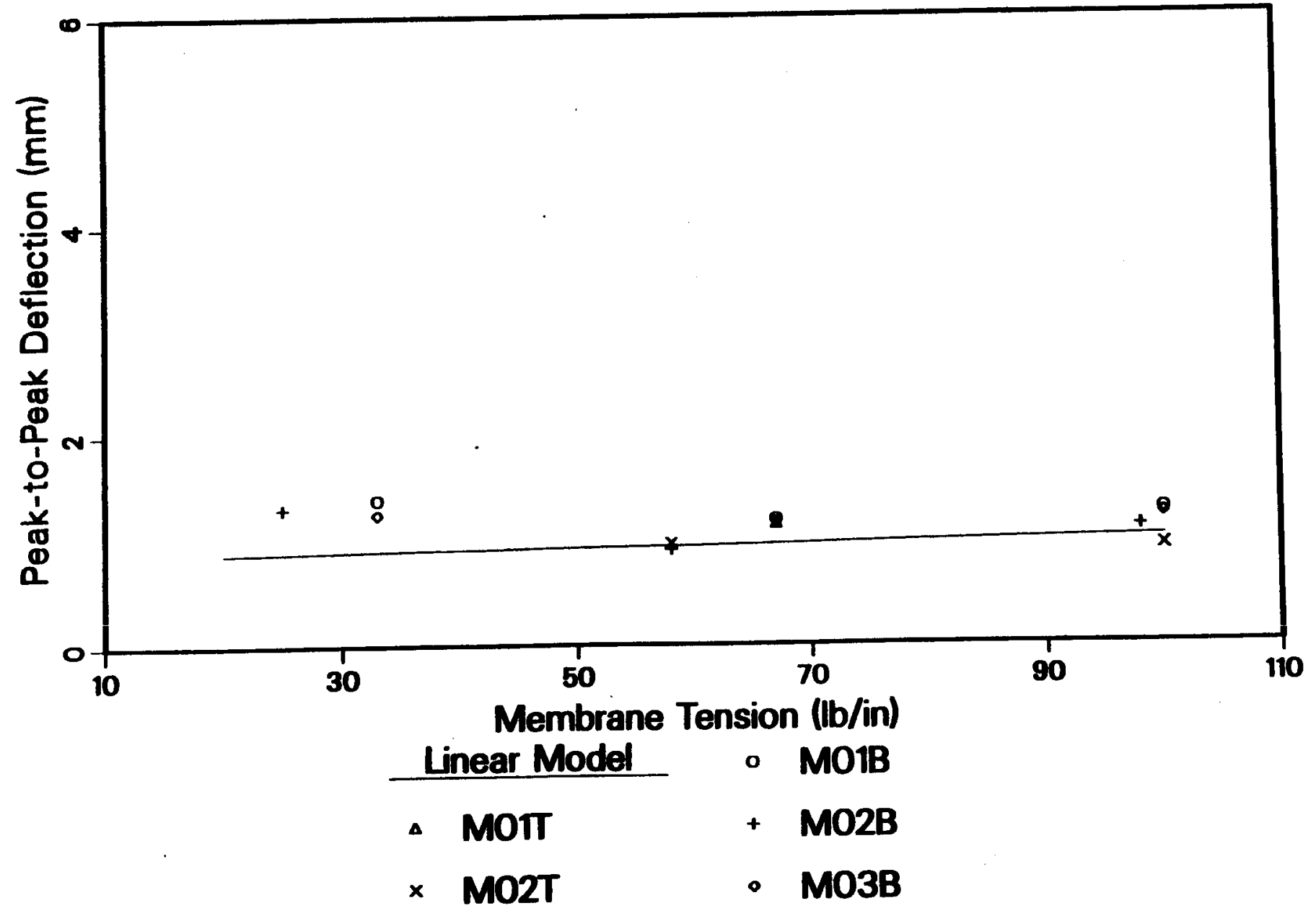

Pigure A-5. Peak-to-Peak Magnitude ( $=2 \times$ applitude) of Support-Induced $(n=3)$ Deflection Component on Single-Hembrane Hodules with tind Load of $0.5 \mathrm{in}$. of Water 


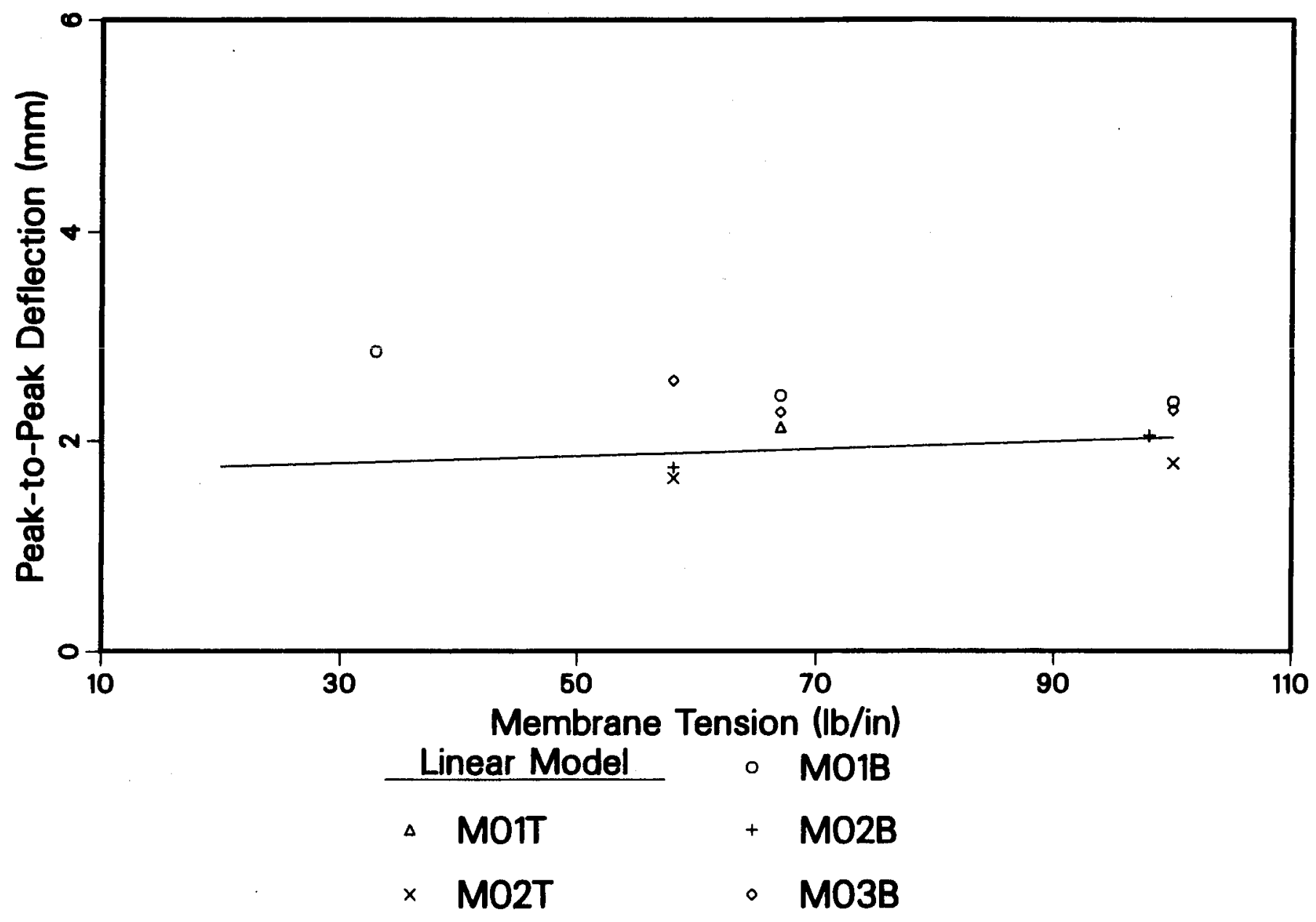

Figure A-6. Peak-to-Peak Magnitude $(=2 \times$ amplitude) of Support-Induced $(n=3)$ Deflection Component on Single-Membrane Modules with Wind Load of 1.0 in. of Water 


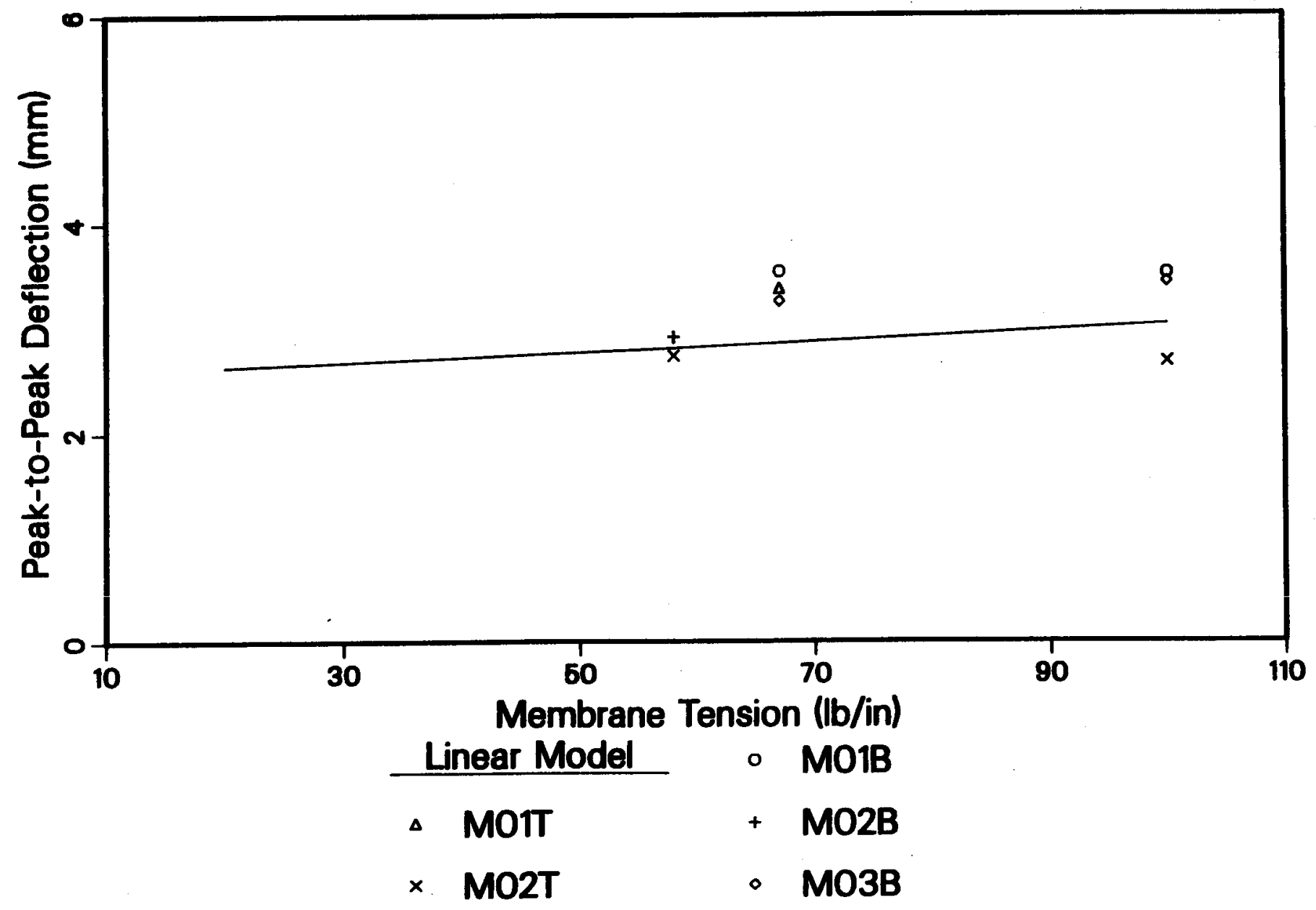

Figure A-7. Peak-to-Peak Magnitude (= $2 \times$ amplitude) of Support-Induced $(n=3)$ Deflection Component on Single-Henbrane Modules with Wind Load of 1.5 in. of Water 


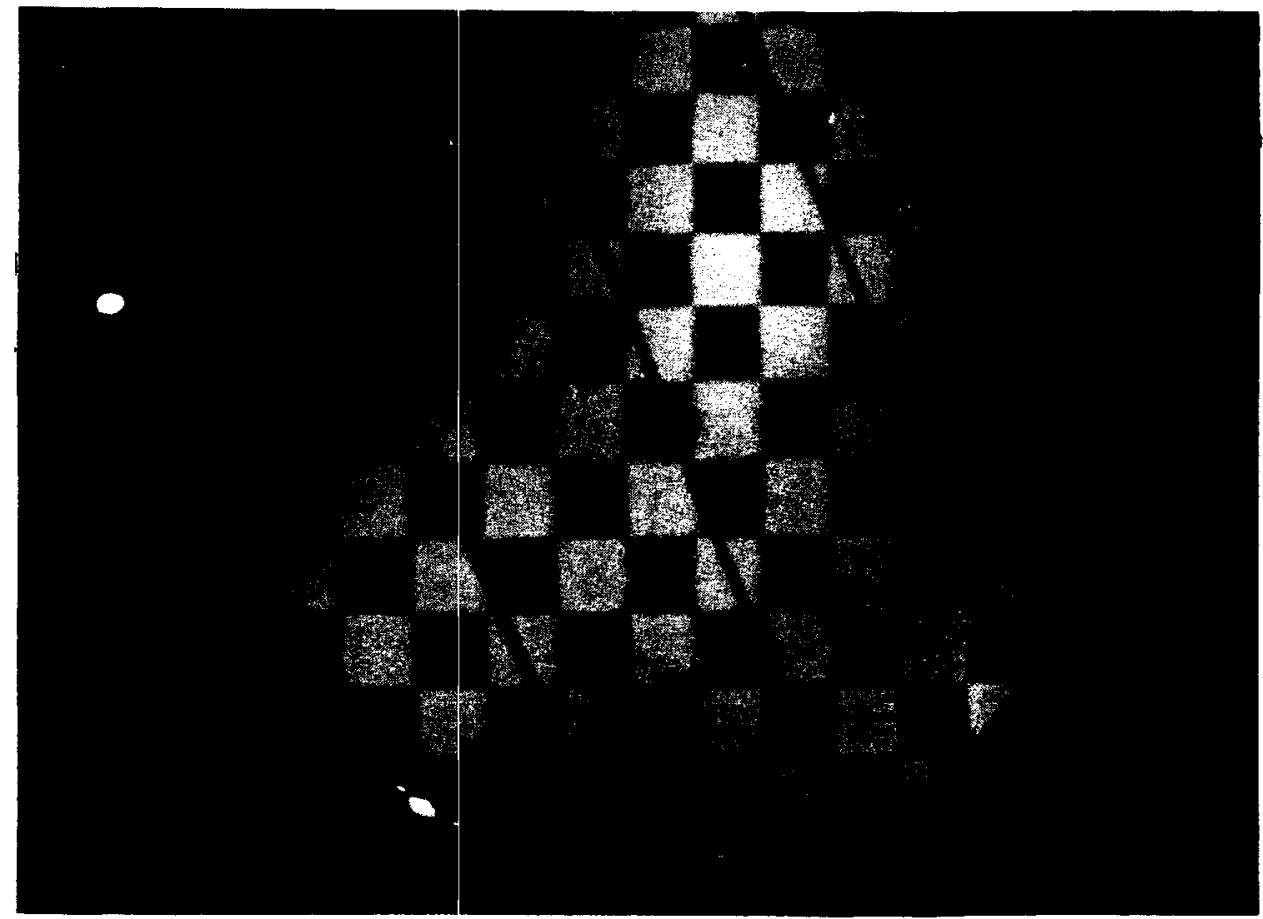

Pigure A-8. Digitized Video Picture of Test M01C400B000. Mirror 1, view C, $40.0 \mathrm{psi}$ in tensioning bladder $=67 \mathrm{lb} / \mathrm{in}$. tension. Bottom weight supported, 0,00 in. of water wind loading.

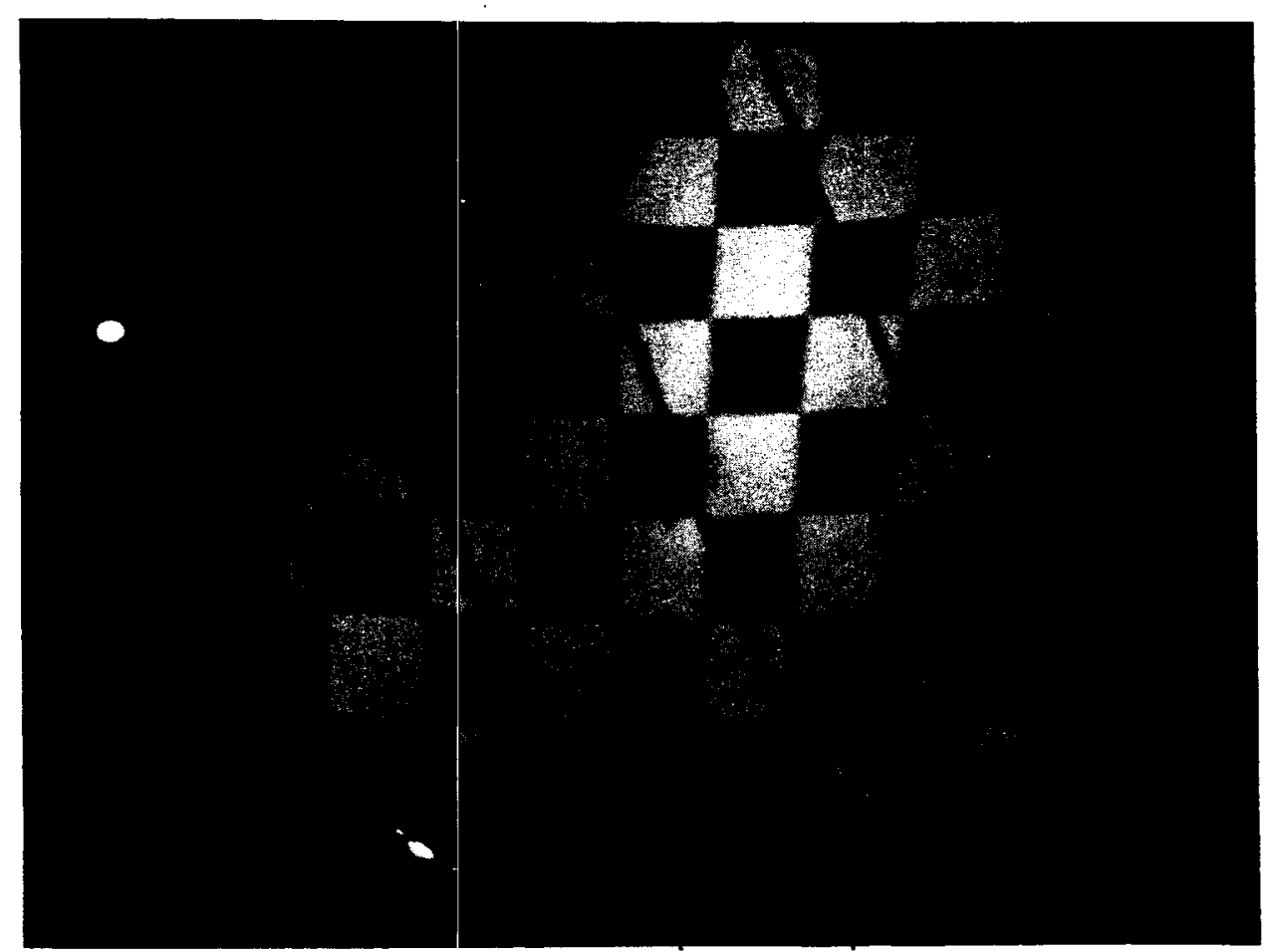

Figure A-10. Digitized Video Picture of Test M01C400B150. Same conditions as in Eigure A-8 except wind loaded to 1.50 in. of water. 

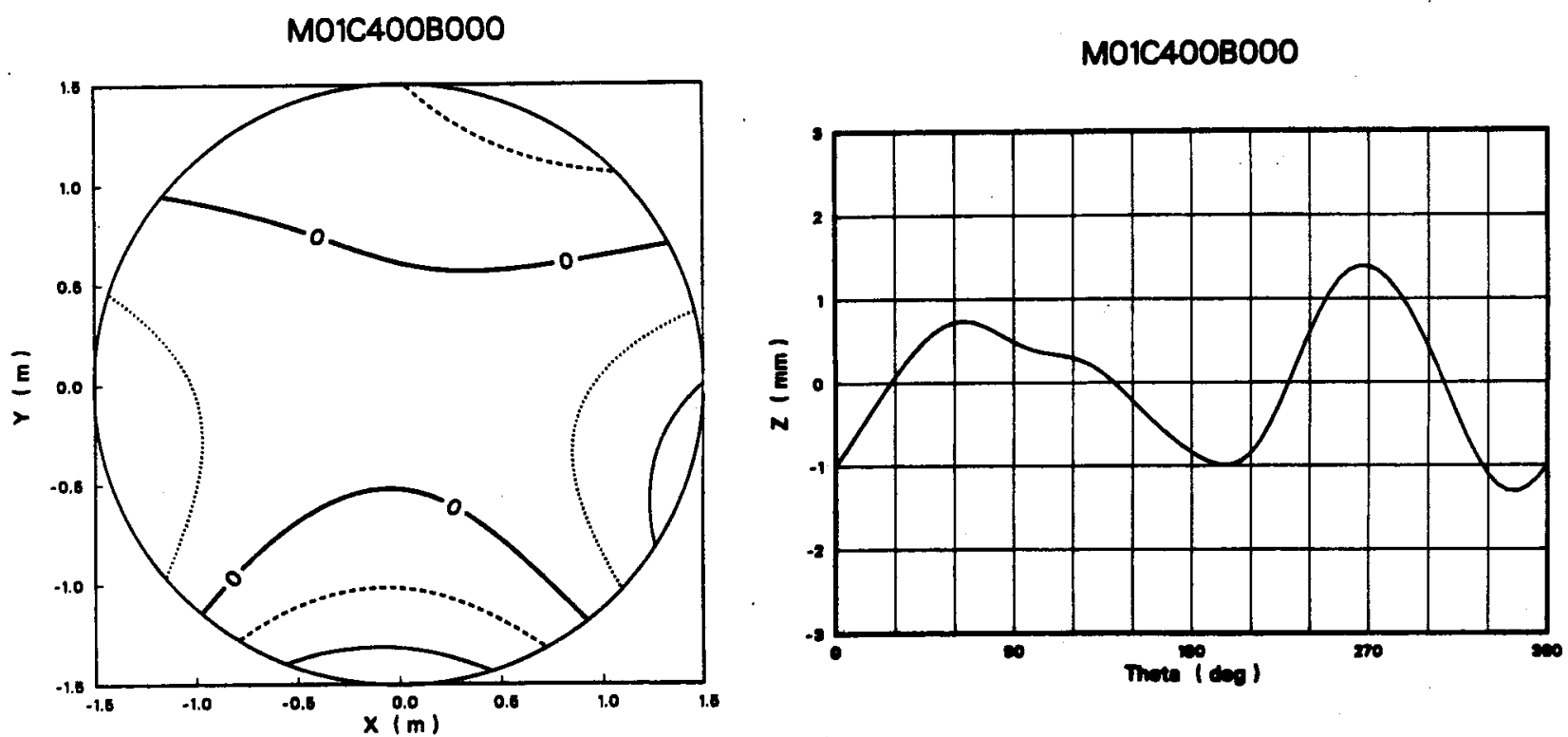

Figure A-9. Implied Membrane and Rim Shapes from Test M01C400B000. (a) Surface contour plot of curve fit to extracted data. Units on contour line are in $\mathrm{mm}$. (b) z-displacement of ring frame vs. $\theta$, measured counterclockwise from the 3 o'clock position.
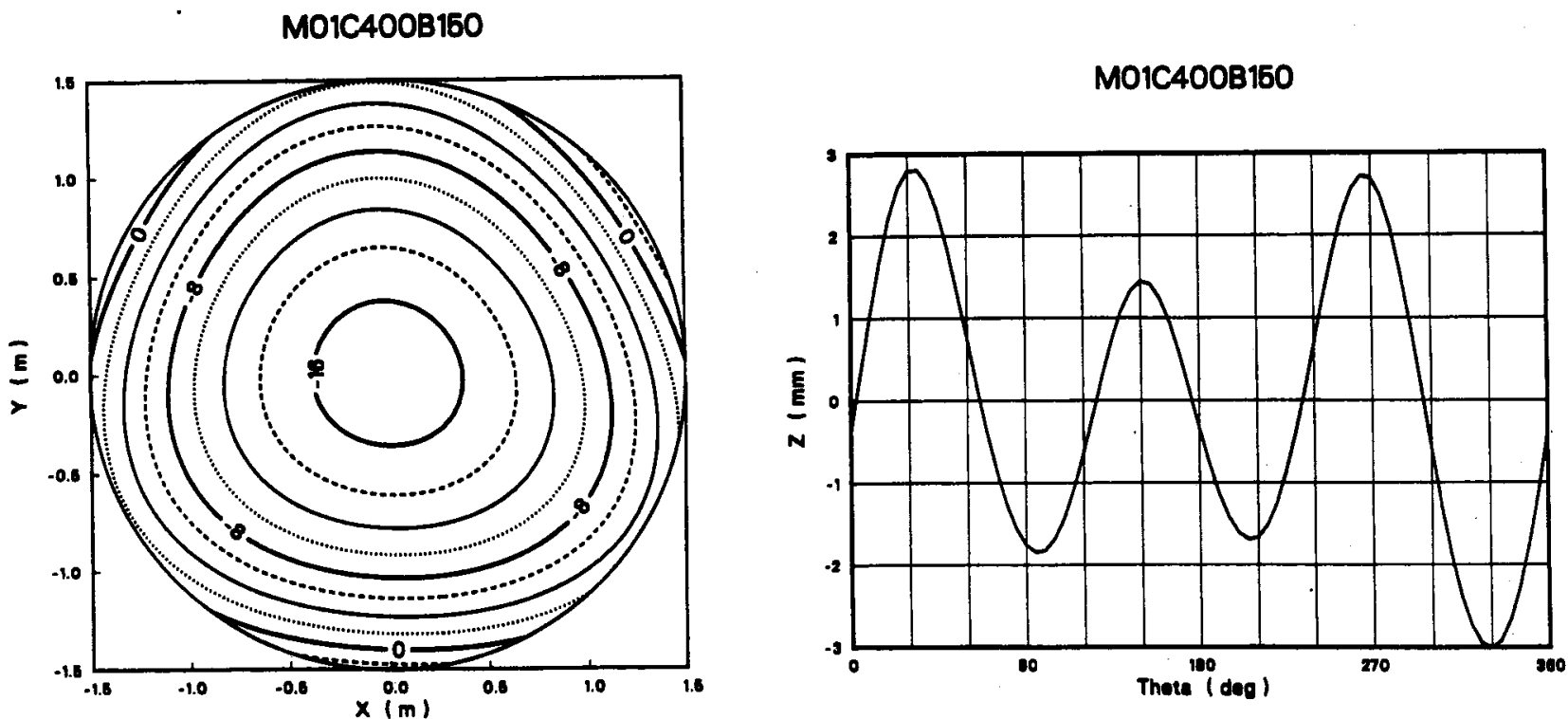

Figure A-11. Implied Membrane and Rim Shapes from Test M01C400B150. Data plotted as in Figure A-9. Note concave dishing caused by negative pressure loading. Note also the emergence of the $n=3$ deflection component in the rim. 


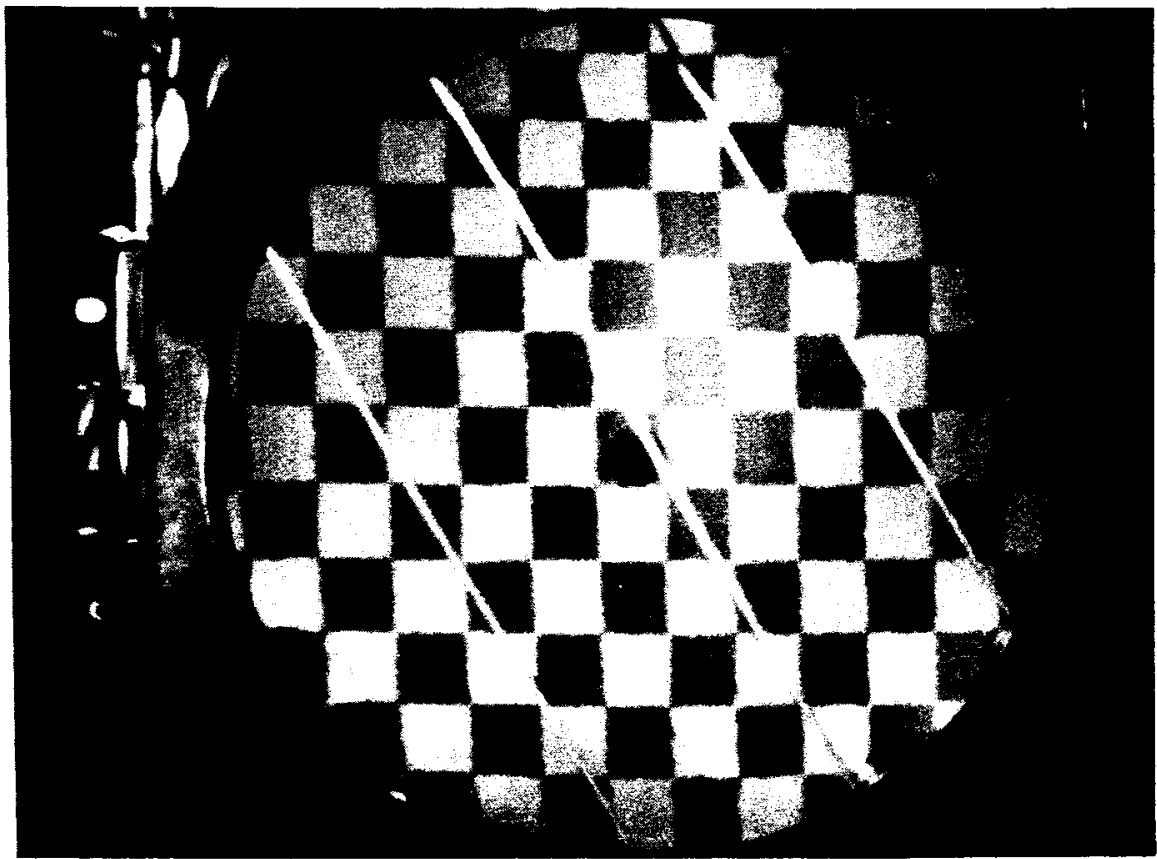

Figure A-12. Digitized Video Picture of Test M03C400B000. Mirror 1, view C, $40.0 \mathrm{psi}$ in tensioning bladder $=67 \mathrm{lb} / \mathrm{in}$. tension. Bottom weight supported, 0.00 in. of water wind loading.

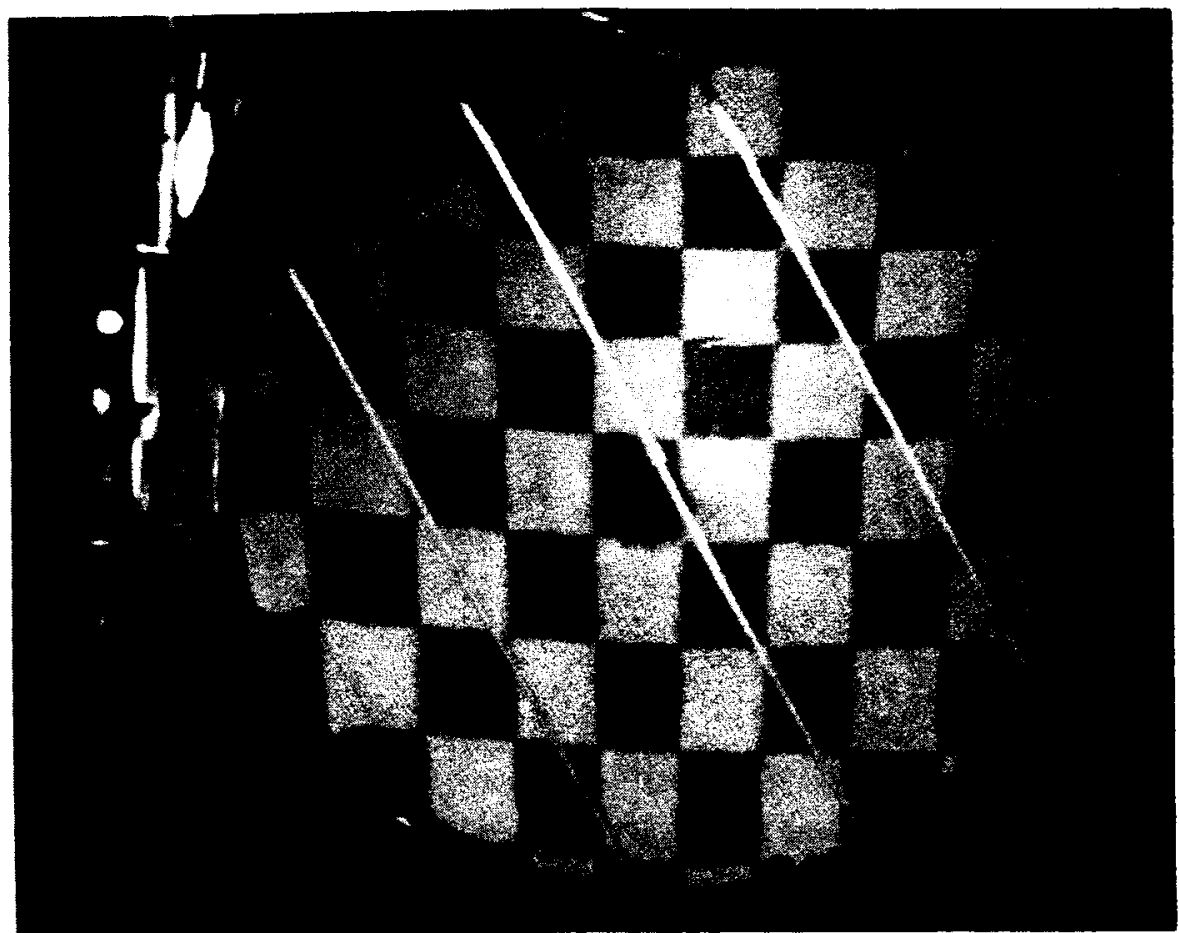

Figure A-14. Digitized Video Picture of Test M03C400B150. Same conditions as in Figure A-12 except wind loaded to 1.50 in. of water. 

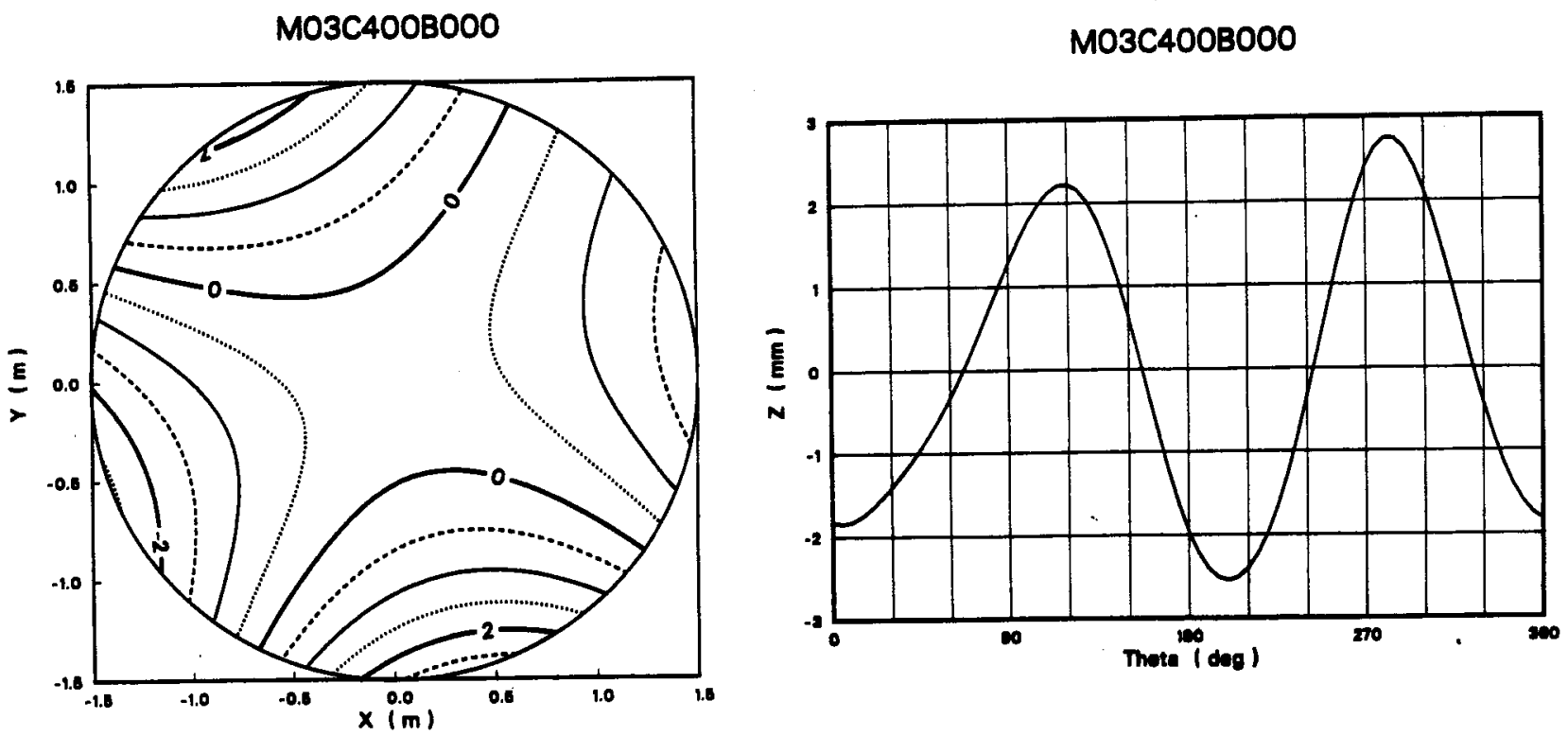

Figure A-13. Implied Membrane and Rim Shapes from Test M03C400B000. (a) Surface contour plot of curve fit to extracted data. Units on contour line are in $\mathrm{mm}$. (b) z-displacement of ring frame vs. $\theta$, measured counterclockwise from the 3 o'clock position.
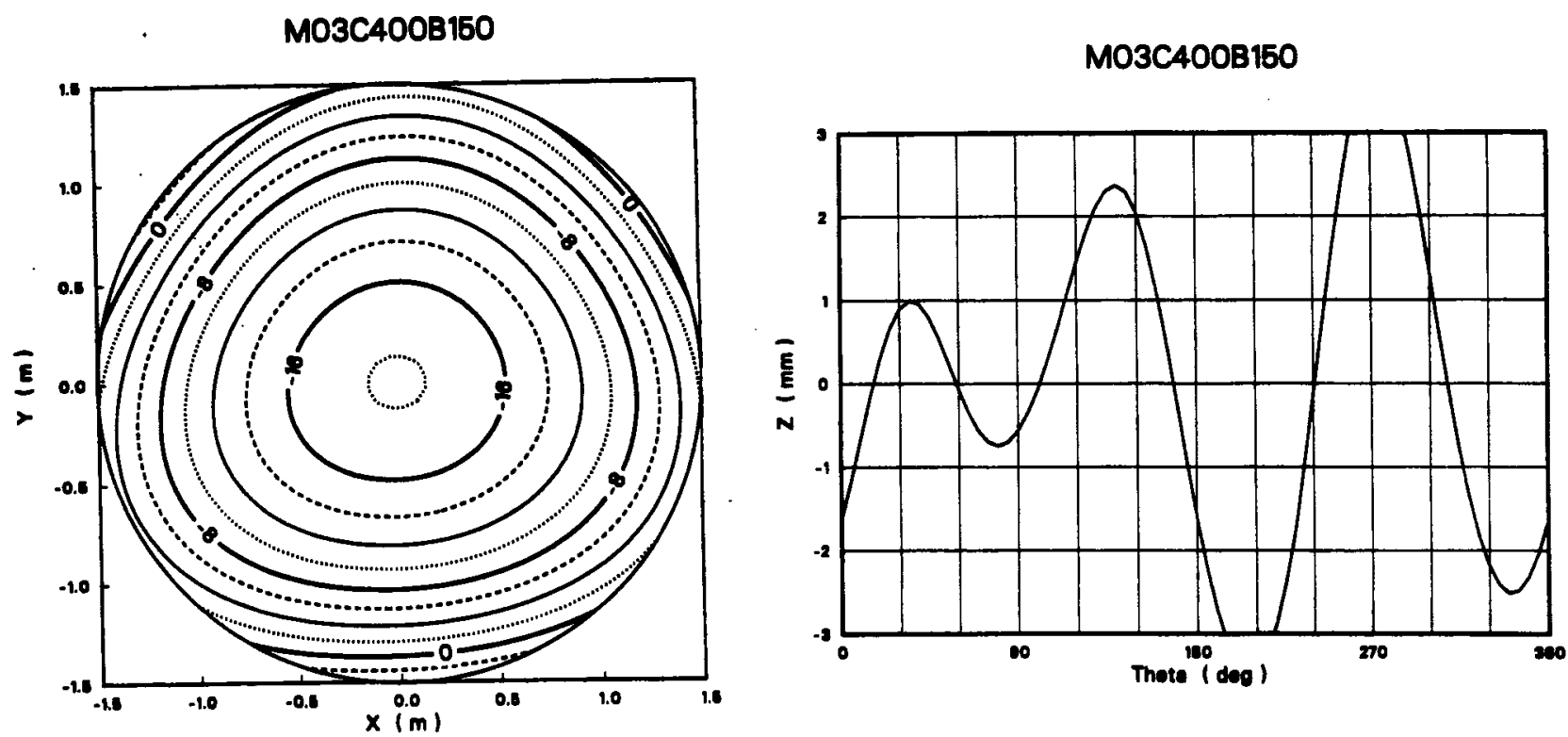

Figure A-15. Implied Membrane and Rim Shapes from Test M03C400B150. Data plotted as in Figure A-13. Note concave dishing caused by negative pressure loading. Note the largest frame deflection is at $\theta=210$ degrees, the 8 o'clock position, where the $n=2$ and $\mathrm{n}=3$ valleys coincide. 

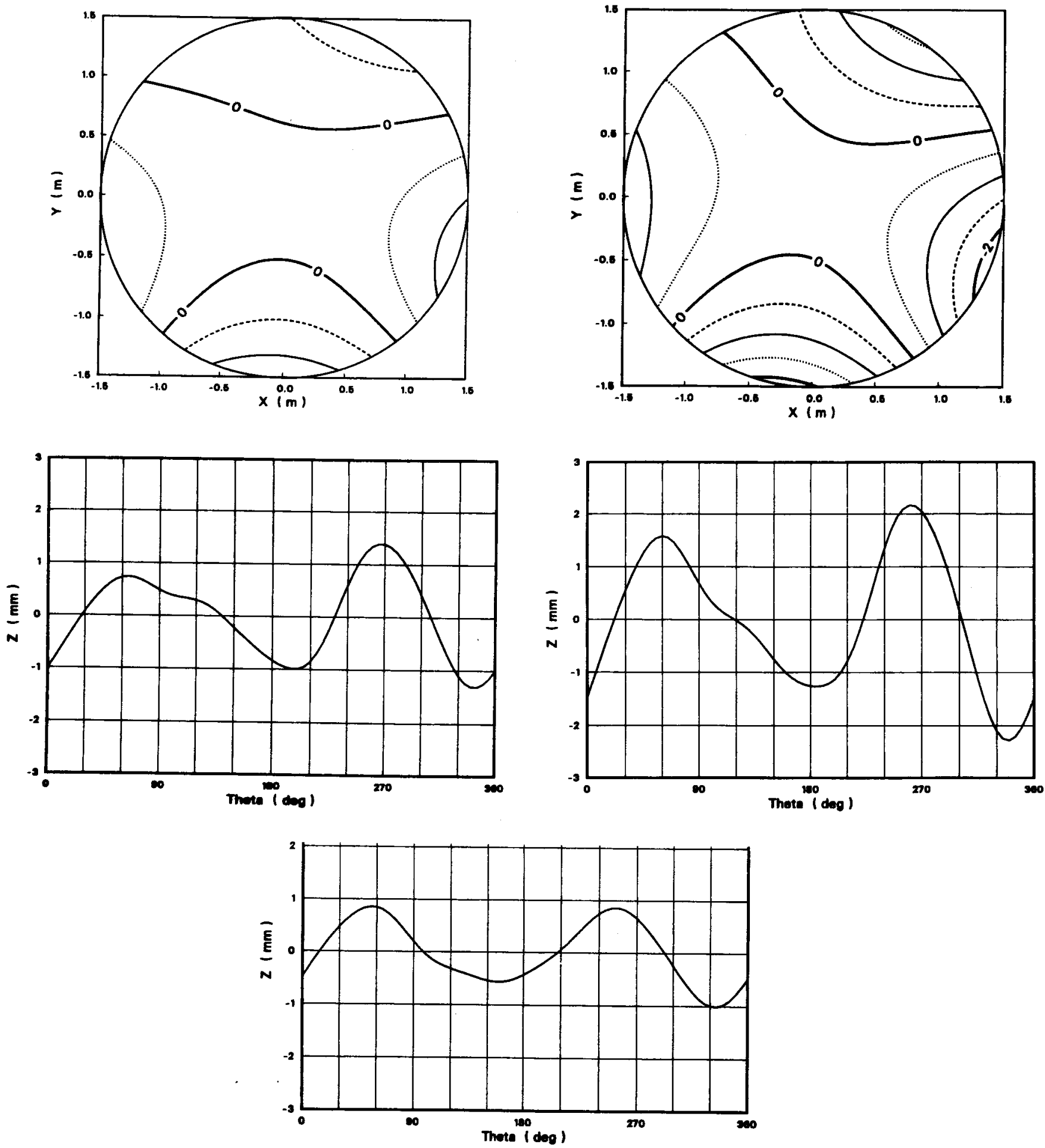

Figure A-16. The Effect of External Bending Moment. Mirror 1, intermediate tension unloaded. On the left, the weight is supported at the bottom brace, where little bending force was imposed. On the right, the weight is supported at the upper two brackets, which imposes moments with an $n=2$ component; high points roughly at 12 and $60^{\prime}$ clock. At the bottom, a plot of the difference in the rim shapes showing the strong $n=2$ component. 


\section{APPEADIX B}

ELEMERTS OR VIDEO OBSERVATION, DIGITIZATIOA, AND ANALYSIS SYSTEM

In this series of structural response tests, a video camera with a telephoto lens observed the mirror test module and reflected virtual image. The camera is a Dage/MTI model SC68, an industrial-grade camera with high spatial and grey-level linearity, as opposed to a simple surveillance camera, which is relatively crude in these critical areas. The lens is a Nikkor Series E, $50 \mathrm{~mm} \mathrm{fl.4}$, which, because of the small format of the Vidicon tube $(\sim 1 / 2 \mathrm{in.})$, is equivalent to a $138-\mathrm{mm}$ telephoto lens on a $35-\mathrm{mm}$ camera. We took the close-up pictures using a Nikkor $300-\mathrm{mm}$ telephoto lens, which would be like using an $800+\mathrm{mm}$ telescope on a $35-\mathrm{mm}$ camera.

The video analysis system used for this project is based on a video digitizer and framestore package produced by Imaging Technology Incorporated, Woburn, Mass., and on software available from G. W. Hannaway and Associates, Boulder, Colo. Although versions of these elements are available for a variety of computers, budgetary and scheduling constraints caused us to use one of our IBM PCs rather than a faster and more powerful minicomputer. (In retrospect, the slowness and relatively small storage capacity of our system critically hampered our data collection and data reduction processes.)

The PC-compatible version of the video package came on a single expansion board, called the PCvision board. This board fits directly into one of the PC's expansion slots and has video input and output jacks. On a signal from the host computer, the video digitizer freezes a frame from the composite video signal coming in through the input jack. The picture is broken into $480 \times 480$ individual cells, or pixels. The digitizer assigns an integer brightness value $Y$ (zero for black, 255 for white) to each pixel. The $480 \times 480$ array of eight-bit integers is stored in a dedicated set of memory chips called the video framestore. The output video display driver continuously examines the framestore and produces a composite video output stream.

The values of integers residing in the framestore array can be read and written using appropriate software. The contents of the framestore can be written to disk and recalled for reviewing at a later time. Our 10-megabyte hard disk was inadequate for storing all of our test data pictures, so we used floppy disks as well. Again, this greatly hampered data analysis efforts.

Various software packages are available to process the displayed image manually. The particular package we used provides subroutines for these processing and access functions that can be called from user-defined, highlevel language programs. 
Our data analysis program retrieved stored frames from floppy disks, located the relative position of the virtual image grid corners, mapped these relative coordinates into real space using observed calibration target data, and calculated membrane surface slopes. Local obstructions and surface distortions sometimes required that a computer operator override the computer's location selection. This process was the most time-consuming part of performing these experiments.

The surface slope data were sent to a mainframe computer with superior graphics capability and speed to process the data and plot the shapes. 


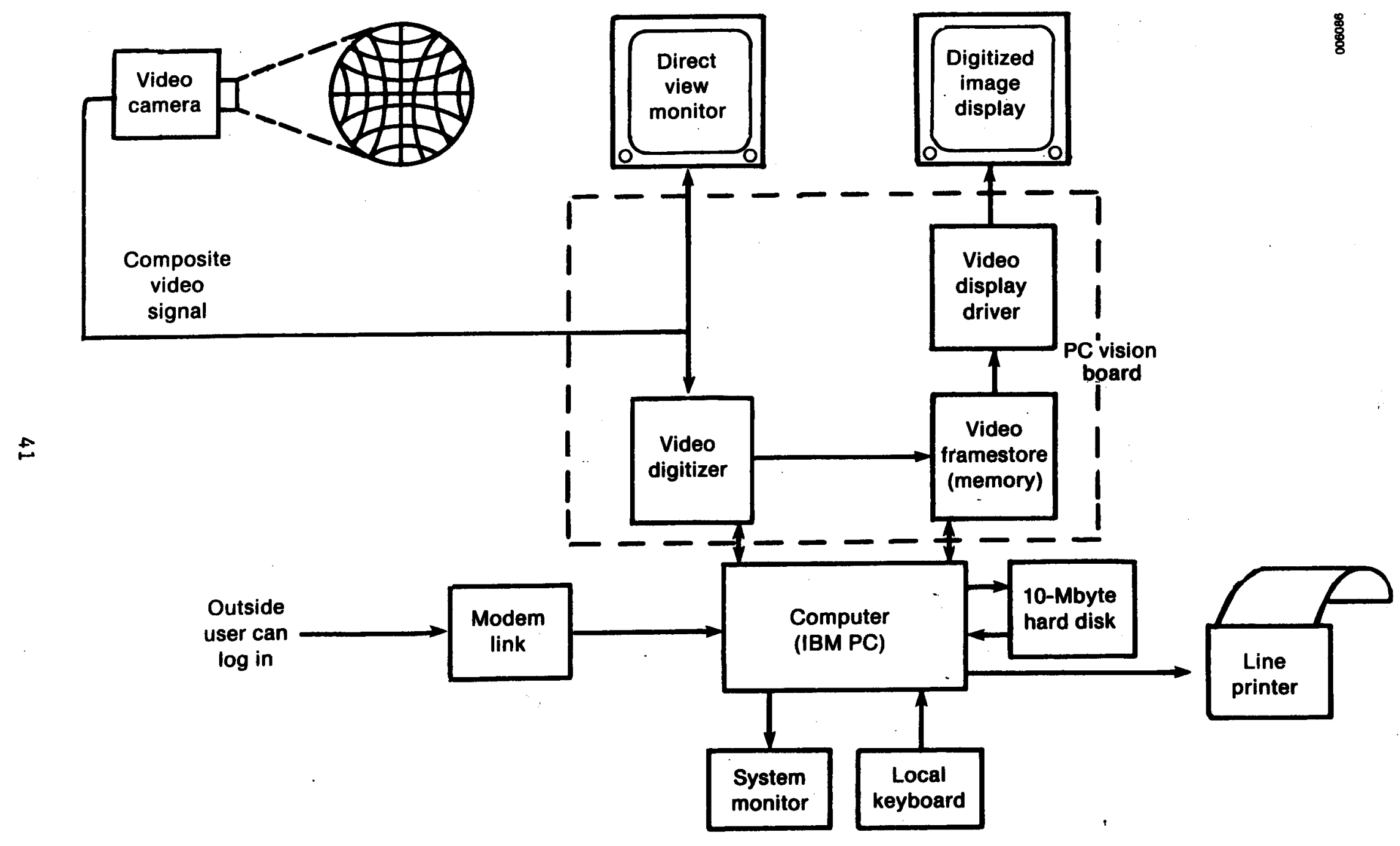

Figure B-1. Video Inage Analysis System. Available digital hardware and software were used, along with SERI software, to extract information from the recorded video images to determine the exact shape of the mirror. 


\section{APPEADIX C \\ ERROR ANALYSIS: SOURCES OF UNCERTAINTY IN RESULTS}

The virtual image technique is a straightforward method of visualizing and quantitatively measuring the directions of surface normal vectors for many points on a mirror; however, it does not directly yield surface deflections. Each snapshot, or frame, yields a self-consistent field of surface normals, each with an associated error band or tolerance. In this series of tests the sources of measurement error are numerous, but all are of a manageable magnitude.

Visually, the most noticeable source of uncertainity arises from the reflective quality of the mirror. These 3-meter modules have reflective surfaces (3M's ECP244) of an aluminized acrylic film with an adhesive backing. At $16+$ meters from the mirror, the slightly scattering metallized plastic film does not reflect a sharp virtual image of the checkerboard grid but blurs the edges of the squares together. Also, because the adhesive backing is wavy, oriented along the roll direction of the film, additional image scatter occurs in the direction perpendicular to the waves.

These effects are illustrated in Figure $C-1(a)$, in which a $300-\mathrm{mm}$ lens was substituted for the $50-\mathrm{mm}$ lens used for the structural tests. The roll direction in the mirror material is clearly discernible, tipped about 20 degrees to the left of vertical, running parallel to the tape-joint splice. (The membrane splices were tipped off-vertical to keep the tape-joints between substrate sheets from obscuring adjacent grid intersections.) Using a large camera aperture with sharp focus in the virtual image plane instead of the mirror plane helps to see past any local effects of the waves on the image, as in Figure $\mathrm{C}-1(\mathrm{~b})$. This blurring made the transition from the light to dark square appear to be about one-tenth the height of one square. Each corner, which is the intersection of two dark and two light regions, appears as a "saddle point" of measured reflected intensities, making it more difficult to tell precisely where on the mirror the corner of the checkerboard grid really is. Under otherwise ideal conditions, we judge the resulting uncertainty in locating the grid corner in the virtual image to be about $1 / 4 \mathrm{mrad}(1 / 2 \mathrm{mrad}$ width at one standard deviation).

The second most noticeable source of data uncertainty comes from local distortions in the structural metal membrane. Since we are trying to characterize the gross shape of the membrane and frame combination, these local problems are not of interest. In these cases the computer operator can manualiy override the simple computer pattern recognition routine in selecting the location of the grid point by extrapolating information from adjacent regions without exaggerated local distortions. Figure C-2 illustrates one such case. The membrane has a slight crease that makes the grid corner appear at a point not representative of the macroscopic shape of the membrane in that vicinity. The computer software locates the corner at point $A$. However, in this case the operator should and did override this selection and choose point $B$ as being more representative of the gross membrane shape. The magnitude of this error depends on the quality of the substrate membrane and on the membrane tension. Based on the size of the local distortions 


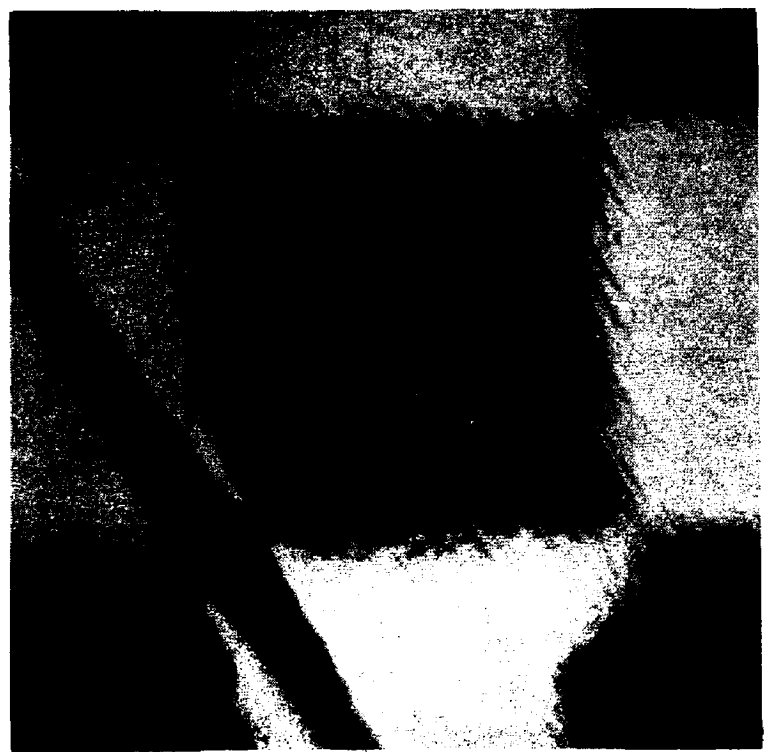

(a) Large aperture, mirror surface In tIght focus

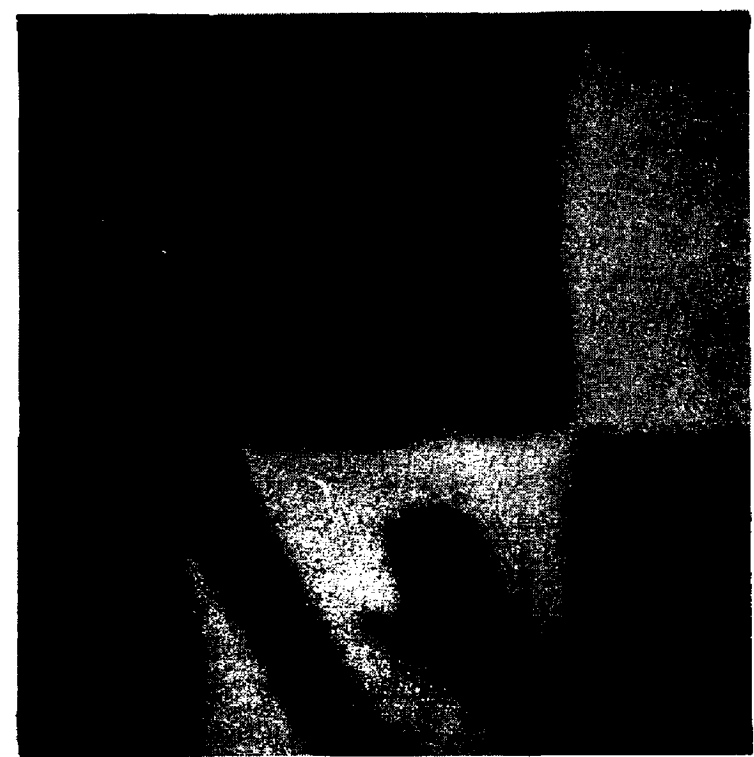

(b) Large aporture, virtual image in beet focus

Pigure C-1. Magnified Views of the Mirror's surface. In (a) the telescopic lens is in sharp focus on the mirror itself. From this long distance, small local defects and ripples are easily discernable. In (b) we see the same view with the lens in focus on the virtual image, which appears twice as far away. The ripples and defects in the mirror cause the image to be blurred but recognizable.

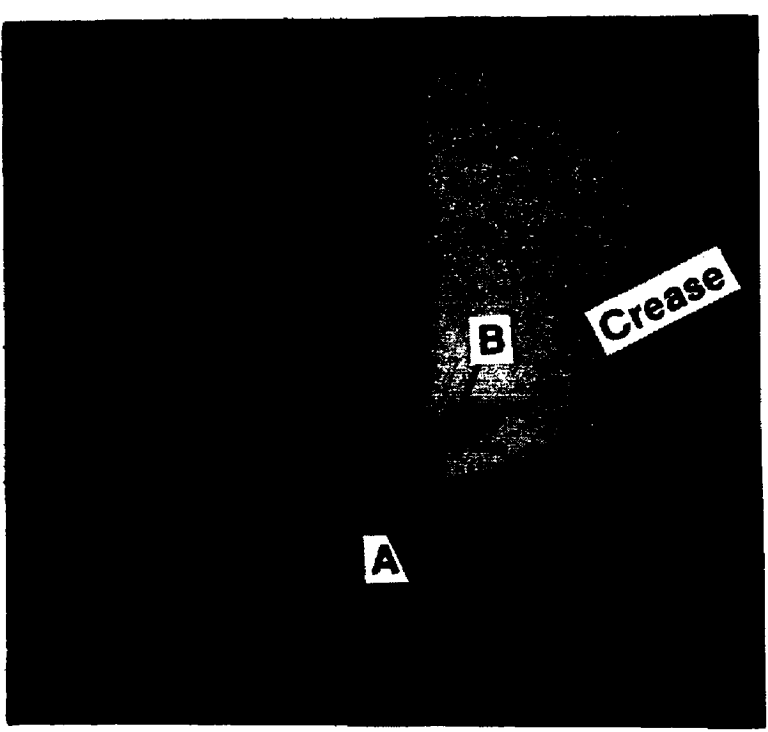

Figure C-2. Data Analysis Is Coaplicated by Local Defects. The slight crease in the membrane causes a repetition and dislocation of the virtual image locally. Without the crease, the vertex would probably appear at $B$.

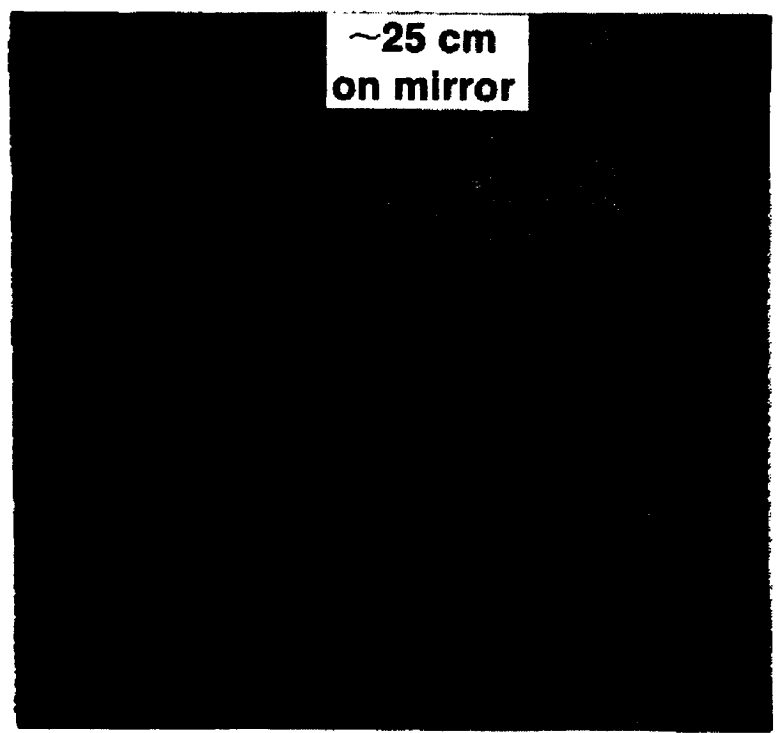

Bigure C-3. Effect of Large-scale Ripples. The waves that cause these distortions in the virtual image are about $10-20 \mathrm{~cm}$ wide and slope less than $2 \mathrm{mrad}$. Maximum displacement from planar is 1 ess than $0.1 \mathrm{~mm}$. 
observed in the virtual image, as in Figure $C-3$, we estimate the typical size of the deflections to be less than 1 mrad (if the membrane is under tension).

Another source of measurement uncertainty appears in when digitizing the image. Each video frame is broken into $480 \times 480$ discrete pixels. A standard monitor display is not square, and a pixel is wider than it is tall. The measured brightness (called gamma) of each pixel is quantized as an 8-bit number; zero is darkest and 255 is brightest. We wrote a software package that can automatically search the entire digitized frame of information and locate the virtual image grid corners. In our scheme we made no attempt to locate the grid corners more precisely than to the closest pixel. In most cases a human looking at a blown-up portion of the digitized picture can still determine where the corner is with a precision finer than one pixel; but that much resolution was deemed unnecessary and would require an inordinate amount of operator interaction. Still, because of the discrete nature of the digitized picture, the corner would appear to lie midway between the centers of two pixels or at the center of a three- or four-pixel cluster. In these cases the computer routine would choose a nearby pixel, and the operator would be called upon to exercise some human pattern recognition and judgment about which pixel was the best guess for the location of the corner. Note that this discreteness in location imposes noise into the data. However, a one-pixel error in location causes only a $0.4-\mathrm{mrad}$ error in the mirror slope calculation.

A fourth source of absolute error is the spatial nonlinearities in the optics and electronics of the video camera. This was largely mitigated by spatial calibration using a second grid pattern. A screen with this grid was

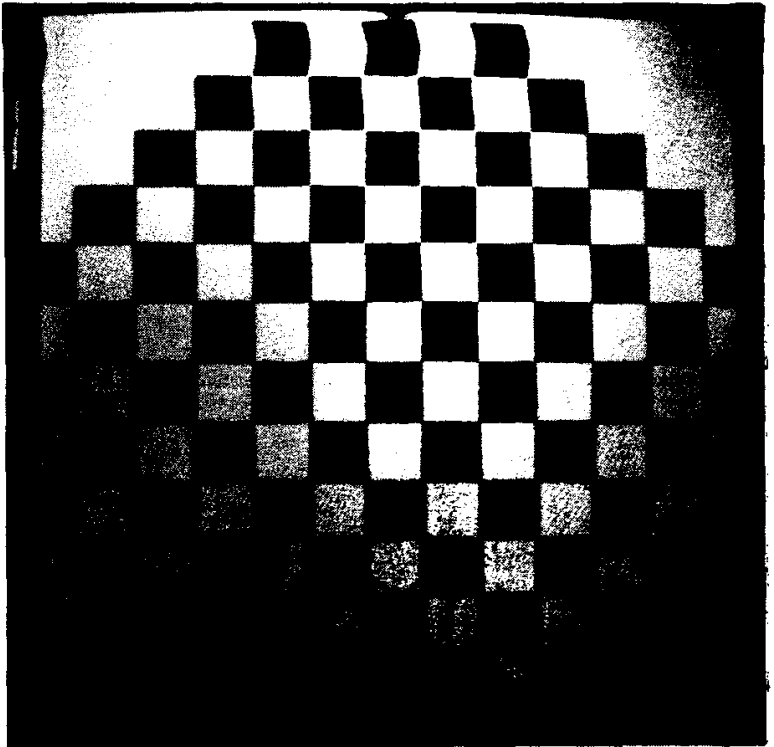

Figure C-4. Direct View of Camera Calibration Target. Mirror images are compared with this known calibration target image to cancel any distortions in the camera optics or electronics. placed in front of the mirror and viewed directly (Figure C-4), establishing an absolute linear scale within the video space. With these known landmarks in the video plane, the locations of virtual image points on a mirror test frame are mapped into real space from video coordinates.

We used the same discrete location scheme on the calibration frame, which caused low level non-Gaussian noise in the camera calibration data, but its effect is diminished in the mapping process, which is an interpolation scheme. The real 10cation of a virtual image grid corner is obtained by comparing its video coordinate location to the four closest known calibration points. The effect of an error in one of the four calibration points when calculating the location of the virtual image grid corner depends on 
how close the point comes to that calibration point. The one-dimensional analogy is that the square distribution of error in the calibration data causes a sawtooth error distribution in the mirror slope data.

Since the significant issue in these structural tests is not the absolute but the relative shape of the mirror, i.e., the difference between the loaded and unloaded shape, this error is immaterial as long as the same calibration data are used on all the mirror data frames within a test series.

We were concerned that we would not obtain enough data from a single frame to average out these errors and allow us to fully characterize the mirror's shape, especially in the simulated wind load cases in which the dishing of the membrane greatly magnified the image of the target, pushing many of the grid points outside the mirror's aperture. We avoided this problem by shooting multiple frames of each structural test case, each with the mirror tilted at a slightly different angle to the optical axis of the observation system. The tilt caused the position of the virtual image grid to shift so a different set of points was sampled each time. The surface normals computed for each frame exhibit a bias in direction according to the module tilt, a bias that can easily be subtracted from the data afterward, yielding surface normals in mirror axis coordinates instead of instrument axis coordinates. The data from the multiple frames of otherwise identical tests were then combined to produce a superset of data describing the mirror shape in that loading condition. A small amount of noise was inserted into the data at that point that corresponded to the uncertainty of the tilt correction factor for each frame. 


\section{SELECTED DISTRIBUTION LIST}

Acurex Solar Corporation

485 Clyde Ave.

Mt. View, CA 94042

Mr. Don Duffy

Advanco Corporation

40701 Monterey Ave.

Palm Desert, CA 92260

$\mathrm{Mr}$. Byron Washom

Arizona Public Service Company

P.0. Box 21666

Phoenix, AZ 85036

Mr. Eric Weber

A.T.A.

12860 W. Cedar Drive

Lakewood, CO 80228

$\mathrm{Mr}$. Jim Wolfe

BDM Corporation

1801 Randolph SE

Albuquerque, MM 87106

Battelle Pacific NW Laboratory

P.0. Box 999

Richland, WA 99352

Dr. Ben Johnson

Dr. Kevin Drost

Mr. Thomas Williams

Bechtel Corporation

P.0. Box 3965

San Francisco, CA 94119

Mr. Pascal DeLaquil

Black and Veatch Consulting

Engineers

1500 Meadow Lake Parkway

Kansas City, MO 64114

Dr. Charles Grosskreutz

Brumleve, Dr. Tom

Consultant

1512 N. Gate Road

Walnut Creek, CA 94598

Colorado State University

Department of Civil Engineering

Ft. Collins, CO 80523

Dr. Jon Peterka
Dan-Ka Products, Inc. 3862 S. Kalamath

Englewood, CO 80110

Mr. Daniel Sallis

Department of Energy/HQ

Forrestal Building

1000 Independence Ave., SW

Washington, DC 20585

Dr. H. Coleman

Mr. S. Gronich

Mr. C. Mangold

Mr. M. Scheve

Mr. Frank Wilkins

Electric Power Research Institute

P.0. Box 10412

Palo Alto, CA 94303

Mr. Donald Augenstein

Entech, Incorporated

P.0. Box 612246

DFW Airport, TX 75261

Mr. Walter Hesse

Gas Research Institute

8600 West Bryn Mawr Ave.

Chicago, IL 60631

Mr. Keith Davidson

Georgia Institute of Technology

Atlanta, GA 30332

Mr. Robert Cassanova

Jet Propulsion Laboratory

4800 Oak Grove Drive

Pasadena, CA 91109

Mr. M. J. Argoud

Mr. E. W. Dennison

LaJet Energy Company

P.0. Box 3599

Abilene, TX 79604

Mr. Monte McGlaum

Luz Engineering Corp.

15720 Ventura Blvd.

Suite 504

Encino, CA 91436

Dr. David Kearney 
Martin Marietta

P.O. Box 179

Denver, CO 80201

Mr. Tom Tracey

McDonnell Douglas Astronautics Company

5301 Bolsa Ave.

Huntington Beach, CA 92647

Mr. Jim Rogan

Meridian Corporation

5113 Leesburg Pike

Suite 700

Falls Church, VA 22041

Mr. Dinesh Kumar

Midwest Research Institute

425 Volker Blvd.

Kansas City, MO 64110

Mr. R. L. Martin

Mr. Jim Williamson

3M Corporation

3M Center Building, 207-1W-08

St. Paul, MN 55101

Mr. David Hill

Mr. Burton A. Benson

NASA-Johnson Space Center

MASA Road One - EPS

Houston, TX 77058

Mr. William Simon

NASA Lewis Research Center

21000 Brookpark Road

Cleveland, $\mathrm{OH} \quad 44135$

Dr. Dennis Flood

National Bureau of Standards

Building 221, Room 252

Gaithersburg, MD 20899

Mr. Joseph Richmond

Pacific Gas and Electric Company 3400 Crow Canyon Rd.

San Ramon, CA 94583

Mr. Gerry Braun

Mr. Joe Iannucci
Rockwell International

Energy Systems Group

8900 De Soto Ave.

Canoga Park, CA 91304

Mr. Tom H. Springer

Sandia National Laboratories

Solar Department 8453

Livermore, CA 94550

Mr. J. C. Swearengen

Mr. A Skinrood

Mr. R. A. Rinne

Sandia National Laboratories

Solar Energy Department 6220

P.0. Box 5800

Albuquerque, NM 87185

Mr. John Otts

Mr. James Leonard

Mr. Donald Schuler

Science Applications, Inc. 10401 Rosselle Street.

San Diego, CA 92121

Dr. Barry Butler

Solar Energy Industries Association 1717 Massachusetts Ave. NW No. 503 Washington, DC 20036

Mr. Carlo La Porta

Mr. David Goren

Mr. Hal Seilstad

Solar Energy Research Institute

1617 Cole Blvd.

Golden, CO 80401

Mr. B. P. Gupta

Dr. L. J. Shannon

Solar Kinetics, Inc.

P.0. Box 47045

Dallas, TX 75247

Mr. Gus Hutchison

Southern California Edison

2244 Walnut Grove Ave.

Rosemead, CA 91770

Mr. Joe Reeves 
Southwest Research Institute 6220 Culebra Road

San Antonio, TX 78238

Mr. Danny M. Deffenbaugh

Texas Tech University

Dept. of Electrical Engineering

Lubbock; TX 79409

Mr. Edgar A. O'Hair

Physics Department

Ms. Virginia K. Agarwal

University of Arizona

College of Engineering

Tucson, AZ 85721

Dr. Kumar Ramohalli

University of Arizona

Dept. of Electrical Engineering

Tucson, AZ 85721

Dr. Roger Jones
University of Chicsgo

Enrico $\overline{\boldsymbol{s}}$ ecul Insticute

5640 S. E11is Ave.

Chicago, IL 60637

Dr. R. Winston

Dr. J. O'Gallagher

University of Houston

4800 Calhoun

106 SPA Building

Houston, TX 77004

Dr. Alvin Hildebrandt

Dr. Lorin Vant-Hull

University of Illinois

Dept. of Mechanical and Industrial

Engineering

1206 W. Green Street

Urbana, IL 61801

Dr. Art Clausing 


\begin{tabular}{|c|c|c|}
\hline $\begin{array}{c}\text { Document Control } \\
\text { Page }\end{array}$ & \begin{tabular}{|l|l|} 
1. SERI Report No. & 2. NTIS Accession No. \\
SERI/TR-253-2736 & \\
\end{tabular} & 3. Recipient's Accession No. \\
\hline \multirow{3}{*}{\multicolumn{2}{|c|}{$\begin{array}{l}\text { 4. Title and Subtitle } \\
\text { Single, Stretched-Membrane, Structural Module } \\
\text { Experiments }\end{array}$}} & \multirow{2}{*}{$\begin{array}{l}\text { 5. Publication Date } \\
\text { February } 1986\end{array}$} \\
\hline & & \\
\hline & & 6. \\
\hline \multicolumn{2}{|l|}{$\begin{array}{l}\text { 7. Author(s) } \\
\text { Richard L. Wood }\end{array}$} & 8. Performing Organization Rept. No. \\
\hline \multirow{2}{*}{\multicolumn{2}{|c|}{$\begin{array}{l}\text { 9. Performing Organization Name and Address } \\
\text { Solar Energy Research Institute } \\
\text { A Division of Midwest Research Institute } \\
1617 \text { Cole Boulevard } \\
\text { Golden, Colorado } 80401-3393\end{array}$}} & \multirow{2}{*}{$\begin{array}{l}\text { 10. Project/Task/Work Unit No. } \\
\qquad 5111.31 \\
\text { 11. Contract (C) or Grant (G) No. } \\
\text { (C) } \\
\text { (G) }\end{array}$} \\
\hline & & \\
\hline \multicolumn{2}{|c|}{ 12. Sponsoring Organization Name and Address } & $\begin{array}{l}\text { 13. Type of Report \& Period Covered } \\
\text { Technical Report }\end{array}$ \\
\hline \multicolumn{3}{|l|}{ 15. Supplementary Notes } \\
\hline \multicolumn{3}{|c|}{$\begin{array}{l}\text { 16. Abstract (Limit: } 200 \text { words) } \\
\text { This report describes tests done on stretched-membrane heliostats used to reflect solar } \\
\text { radiation onto a central receiver. The tests were used to validate prior analysis and } \\
\text { mathematical models developed to describe module performance. The modules tested were } \\
\text { three meters in diameter and had reflective polymer film laminated to the membrane. The } \\
\text { frames were supported at three points equally spaced around the ring. Three modules were } \\
\text { pneumatically attached with their weight suspended at the bottom support, two were } \\
\text { pneumatically attached with their weight suspended from the upper mounts, and one was rigidly } \\
\text { attached with its weight suspended at the bottom mount. By varying the membrane tension we } \\
\text { could simulate a uniform wind loading normal to the mirror's surface. A video camera I5+ } \\
\text { meters away from the mirror recorded the virtual image of a target grid as reflected by the } \\
\text { mirrors' surface. The image was digitized and stored on a microcomputer. Using the law of } \\
\text { reflection and analytic geometry, we computed the surface slopes of a sampling of points on the } \\
\text { surface. The dominant module response was consistent with prior SERI analyses. The simple } \\
\text { analytical model is quite adequate for designing and sizing sinle-membrane modules if the initial } \\
\text { imperfections and their amplification are appropriately controlled. To avoid potential problems } \\
\text { resulting from the fundamentally } n=2 \text { deformation phenomena, we advise using either } \\
\text { relatively stiffer ring frames or more than three support points. }\end{array}$} \\
\hline \multirow{2}{*}{\multicolumn{3}{|c|}{$\begin{array}{l}\text { 17. Document Analysis } \\
\text { a. Descriptors Heliostats; Solar Thermal Conversic } \\
\text { Solar Reflectors; Mechanical Structı } \\
\text { b. Identifiers/Open-Ended Terms Structural Membrane }\end{array}$}} \\
\hline & & \\
\hline \multicolumn{3}{|l|}{$\begin{array}{l}\text { c. UC Categories } \\
62 a\end{array}$} \\
\hline \multirow{2}{*}{\multicolumn{2}{|c|}{$\begin{array}{l}\text { 18. Availability Statement } \\
\text { National Technical Information Service } \\
\text { U.S. Department of Commerce } \\
5285 \text { Port Royal Road } \\
\text { Springfield, Virginia } 22161\end{array}$}} & 19. No. of Pages \\
\hline & & $\begin{array}{l}\text { 20. Price } \\
\text { A04 }\end{array}$ \\
\hline
\end{tabular}

